\title{
Biomarkers of cholestasis
}

Alanah Pieters ${ }^{1}$, Eva Gijbels ${ }^{1}$, Bruno Cogliati ${ }^{2}$, Pieter Annaert ${ }^{3}$, Lindsey Devisscher ${ }^{4}$, Mathieu Vinken ${ }^{l}$

${ }^{1}$ Department of In Vitro Toxicology and Dermato-Cosmetology, Vrije Universiteit Brussel, Laarbeeklaan 103, 1090 Brussels, Belgium.

${ }^{2}$ Department of Pathology, School of Veterinary Medicine and Animal Science, University of São Paulo, Av. Prof. Dr. Orlando Marques de Paiva 87, Cidade Universitária, 05508-270, São Paulo, Brazil.

${ }^{3}$ Drug Delivery and Disposition, Department of Pharmaceutical and Pharmacological Sciences, Katholieke Universiteit Leuven, ON II Herestraat 49, box 921, 3000 Leuven, Belgium.

${ }^{4}$ Basic and Applied Medical Sciences, Gut-Liver Immunopharmacology Unit, Faculty of Medicine and Health Sciences, Ghent University, C. Heymanslaan 10, 9000 Ghent, Belgium.

Correspondence: Prof. Mathieu Vinken, Ph.D., Pharm.D., E.R.T., Department of In Vitro Toxicology and Dermato-Cosmetology, Vrije Universiteit Brussel, Laarbeeklaan 103, 1090 Brussels, Belgium; Tel: +32 247745 87; e-mail: mathieu.vinken@vub.be.

\begin{abstract}
Cholestasis is a pathological condition that may occur in a variety of diseases, grouped as cholestatic liver diseases. When left untreated, cholestatic circumstances may lead to harmful liver problems, such as fibrosis and cirrhosis, with possibly even death as a consequence. Hence, early detection of cholestasis allowing for customized treatment is critical. The frequent initial asymptomatic character and general complexity of cholestatic liver diseases together with the current lack of a single straightforward biomarker complicate this task up-to-day. With the emergence of the 'omics' era, scientific approaches in biomarker discovery significantly altered. Despite the resulting plethora of possible cholestatic
\end{abstract}


indicators, the end of this compelling task in finding a single, clinically applicable biomarker for cholestasis is still out of sight. The long list of criteria to fulfil as ideal biomarker as well as the challenging molecular pathways in cholestatic liver diseases rather advocate for a scenario in which multiple biomarkers, originating from different novel and established domains, will be assessed concomitantly. This review paper gives an overview of the classical clinical and novel molecular biomarkers in cholestasis, with a main focus on their benefits and drawbacks.

Key words: biomarker, cholestasis, liver, omics.

\section{List of abbreviations:}

2-DE two-dimensional gel electrophoresis

5-NT 5'-nucleotidase

ALP alkaline phosphatase

ALT alanine aminotransferase

AOP adverse outcome pathway

AST aspartate aminotransferase

BRIC benign recurrent intrahepatic cholestasis

BSEP bile salt export pump

CFALD cystic fibrosis-associated liver disease

DIC drug-induced cholestasis

GC gas chromatography

GGT $\quad \gamma$-glutamyltransferase

GWAS genome-wide association studies

H3K4 histone H3 lysine 4

HLA human leucocyte antigen

HPLC high-performance liquid chromatography

ICP intrahepatic cholestasis of pregnancy

IgG4 immunoglobuline G4 


$\begin{array}{ll}\text { LC } & \text { liquid chromatography } \\ \text { miR-210 } & \text { microRNA-210 } \\ \text { miRNA } & \text { microRNA } \\ \text { MS } & \text { mass spectrometry } \\ \text { NGS } & \text { next-generation sequencing } \\ \text { NMR } & \text { nuclear magnetic resonance } \\ \text { PBC } & \text { primary biliary cholangitis } \\ \text { PFIC } & \text { progressive familial intrahepatic cholestasis } \\ \text { PSC } & \text { primary sclerosing cholangitis } \\ \text { ULN } & \text { upper limit of normal }\end{array}$

\section{Introduction}

Cholestasis is a general term to denote any pathological status in which bile formation, secretion or flow is chronically or acutely hampered (Jüngst \& Lammert, 2013; Lu et al., 2016; Pollock \& Minuk, 2017). Depending on the anatomical site of this disturbance, cholestasis can be further categorized as intrahepatic or extrahepatic. Hepatobiliary anomalies with cholestasis as major clinical manifestation are collectively termed cholestatic liver diseases and include a variety of disorders with different etiologies, including primary biliary cholangitis ( $\mathrm{PBC}$ ), primary sclerosing cholangitis (PSC), autoimmune hepatitis (AIH) overlap syndrome with $\mathrm{PBC}$ or PSC, immunoglobulin G4 (IgG4) associated cholangitis, cystic fibrosis-associated liver disease (CFALD), progressive familial intrahepatic cholestasis (PFIC), benign recurrent intrahepatic cholestasis (BRIC) type 1 and 2, Alagille syndrome, biliary atresia, intrahepatic cholestasis of pregnancy (ICP) and drug-induced cholestasis (DIC) (EASL, 2009; Nguyen et al., 2014). Cholestasis can co-occur in other diseases as well, but reported prevalence of cholestatic insults are lower than in the typical cholestatic liver diseases (Cao et al., 2015). These pathologies may involve hepatobiliary diseases, such as alcoholic hepatitis, different types of cirrhosis and nonalcoholic fatty liver disease, but also diseases that do not primarily affect the 
liver, such as hematologic diseases, paraneoplastic syndromes and vascular disorders (Cao et al., 2015; EASL, 2009).

Prolonged or severe cholestatic conditions are likely to develop in liver fibrosis, cirrhosis and even hepatocellular or cholangiocarcinoma, with possibly death as final outcome (Pollock \& Minuk, 2017). Unfortunately, current therapies are mostly unspecific and rely on symptomatic treatment rather than coming to grips with the pathological cause (Onofrio \& Hirschfield, 2020). Furthermore, cholestatic liver diseases are frequently only noticed and diagnosed in a more advanced stage, in part due to suboptimal diagnostic tools (EASL, 2009; Onofrio \& Hirschfield, 2020). This justifies the current need for more sensitive and specific biomarkers that allow for early detection and possibility for prognosis of cholestatic liver diseases (Hardy \& Mann, 2016; Marrer \& Dieterle, 2010).

Over the years, the definition of a biomarker, the shortening word for biological marker, has been specified and extended by several groups. The core definition of a biomarker can be resumed as a quantifiable characteristic of measurable biological processes that correlates with the clinical outcome. In order to comply with this description, the perfect biomarker should be highly sensitive and specific for a biological, and consequently pathological, process, implying a clear relationship between the biomarker and the clinical endpoint (Babrak et al., 2019; Marrer \& Dieterle, 2010; Strimbu \& Tavel, 2010a). Accordingly, the biomarker should also display predictive power for clinical outcomes and disease progression and prognosis (Hardy \& Mann, 2016; Strimbu \& Tavel, 2010a). Measurements must be executable in an objective, accurate and reproducible manner (Strimbu \& Tavel, 2010a), and represent the actual patient status instead of portraying incomplete time-depending snapshots (Babrak et al., 2019). Ideally, clinical assessments and analyses should bear low costs and exhibit a non-invasive character.

Clearly, it is hard, if not impossible, to fulfill all these expectations. Even though classical clinical biomarkers are useful in diagnosis and possibly prognosis of cholestasis, they do not allow to unravel the etiology of the cholestatic insult (Babrak et al., 2019; EASL, 2009). With the technological advances in the last 2 decades, the field of 'omics' has made its introduction in research for novel biomarkers in cholestasis, and an enormous amount of data has been generated thanks to high-throughput technology and powerful software. This review paper gives an overview of currently established and possible future 
biomarkers for cholestatic liver diseases, with a main focus on their general advantages and disadvantages, and aims at expanding the reader's insight into the complexity of the search for appropriate cholestatic biomarkers.

\section{Biomarkers of cholestasis}

\subsection{Clinical biomarkers}

\subsubsection{Physical biomarkers}

Although in strict definition not considered a physical biomarker, the patient's clinical presentation is highly important as it represents the first-line read-out of a possible pathological condition and forms the basis for further disease-specific research. At an early stage of cholestasis, patients often remain asymptomatic or present with non-specific clinical symptoms such as fatigue, anorexia, abdominal pain and nausea (EASL, 2009; Jüngst \& Lammert, 2013; Onofrio \& Hirschfield, 2020). Clinical physical manifestations more precisely pointing towards cholestasis include jaundice, scleral ictus, pruritus and skin excoriations due to scratching, xanthoma, skin pigmentation, dark urine and pale feces. Since bile is necessary for the absorption of fat-soluble vitamins, i.e. vitamin $\mathrm{A}, \mathrm{D}, \mathrm{E}$ and $\mathrm{K}$, symptoms related to deficiencies in these vitamins could be indicative for cholestasis as well (Levy \& Lindor, 2003; Phillips et al., 2001).

When the patient's clinical presentation raises the suspicion of cholestasis, a first set of measurements aims at differentiating an intrahepatic from extrahepatic cause by visualizing disease-specific morphological features in the hepatobiliary tract using imaging methods (EASL, 2009). The preferred technique for detection of intrahepatic and extrahepatic bile duct obstructions or dilatations involves abdominal ultrasonography or ultrasound, since it is non-invasive, portable, relatively inexpensive and allows for sufficient sensitivity and specificity (EASL, 2009; Lu et al., 2016; Rogoveanu et al., 2006). On the other hand, the obtained findings are operator-dependent and in some cases certain abnormalities of bile ducts can be missed (Cieszanowski et al., 2000). Computed tomography can overcome these problems, but includes important disadvantages, such as use of radiation and decreased performance in delineating the biliary tree (EASL, 2009; Lu et al., 2016). Magnetic resonance 
cholangiopancreatography is a safe and accurate option to further explore the biliary tree, together with endoscopic ultrasound (EASL, 2009; Lu et al., 2016). Although endoscopic retrograde cholangiopancreatography is considered the gold standard for examination of the biliary tract and extrahepatic obstructions, the use of this technique is reserved for highly specific cases due to a high morbidity and mortality associated (EASL, 2009; Lu et al., 2016).

Chronic cholestatic conditions can eventually burgeon into liver fibrosis and even liver cirrhosis and failure. Therefore, early detection of liver fibrosis, characterized by liver stiffness, is critical in determining the severity and prognosis of the cholestatic disease (Corpechot, 2016). Elastography techniques are state-of-the-art methods for liver elasticity measurements, with vibration-controlled transient elastography being the most widely used (Corpechot, 2016; Patel \& Sebastiani, 2020). This validated ultrasound-based technique displays high reproducibility and accuracy, especially in PBC and PSC, and has several other advantages, such as rapidity of measurements and result obtention, ease in use and bed-sided application (Corpechot, 2016; Patel \& Sebastiani, 2020; Toosi, 2015). Other less practiced ultrasound-based techniques include static elastography, shear wave elastography, acoustic radiation force impulse imaging and magnetic resonance elastography (Frulio \& Trillaud, 2013; Patel \& Sebastiani, 2020).

Assessing clinical physical biomarkers clearly is of utmost importance in identifying possible causes of cholestasis. When combined with other biomarkers, essentially clinical chemistry biomarkers, they have proven useful for diagnostic purposes (EASL, 2009; Pollock \& Minuk, 2017).

\subsubsection{Clinical chemistry biomarkers}

By far the most frequently used biomarkers for detection of cholestasis are clinical chemistry biomarkers, which can be easily assessed by blood sampling.

Two enzymes whose serum concentrations are most frequently analyzed are alanine aminotransferase (ALT) and alkaline phosphatase (ALP), with ALP as prior biomarker for cholestasis. Nevertheless, their distribution is not limited to the liver. ALT can occur under the form of two isoenzymes namely ALT1, present in liver, kidney, fat and heart, and ALT2, detectable in brain, muscle, kidney and fat (Lindblom et al., 2007; Yang et al., 2002). In the case of ALP, at least four different isoenzymes have been 
identified, classified by their site of expression, namely placenta, liver/bone/kidney, intestine and germ cells (Sharma et al., 2014). However, whereas ALT is a cytosolic enzyme, ALP is present at the cell plasma membrane. Consequently, the detergent mode of action inherent to the increased bile acid concentration in cholestasis causes ALP release from the hepatocellular membrane into the systemic circulation (Accatino et al., 1995; Deng et al., 1996; Hatoff \& Hardison, 1982; Lu et al., 2016; Pollock \& Minuk, 2017). Therefore, increased serum ALP concentrations are more indicative for cholestatic injury whereas increased ALT levels point towards hepatocellular damage as such (Pollock \& Minuk, 2017; Vinken et al., 2013). It must be noted that ALP has a half-life of seven days (Price, 1993), making detection of elevated ALP serum concentrations possible even after disappearance of the cause of cholestatic injury, such as obstruction (Pollock \& Minuk, 2017). Importantly, next to liver diseases, bone activity, altered in bone diseases and during childhood, is a significant contributor to serum ALP levels (Lu et al., 2016; Sotil \& Jensen, 2004). Furthermore, external factors, such as pregnancy, smoking and exercise, are also frequently associated with increased serum ALP levels, as well as other rare diseases, including Celiac disease and hyperparathyroidism, albeit to a lesser extent (Sharma et al., 2014; Sotil \& Jensen, 2004). Therefore, ALP as such is not a highly specific biomarker of cholestasis.

In addition to ALT and ALP, aspartate aminotransferase (AST) levels can be assessed in order to calculate the AST/ALT ratio. Values higher than 1.5 are suggestive for intrahepatic cholestasis, whereas lower levels are indicative for extrahepatic obstruction (Hall \& Cash, 2012). However, in clinical settings, AST measurements are less popular due to an unclear advantage over ALP measurements. This is mainly due to the wide tissue distribution of AST. Whereas the mitochondrial isoform is abundantly present in hepatocytes (Rej, 1978), the cytosolic isoform can be found in skeletal and heart muscle, kidneys and red blood cells (Boyde \& Latner, 1962). Release of mitochondrial AST occurs in a similar manner as ALT, hence indicating hepatocellular damage (Ramaiah, 2007; Reichling \& Kaplan, 1988). Cytosolic AST however, can enter the bloodstream under many pathological circumstances, including muscle injury and hemolysis (Ramaiah, 2007; Reichling \& Kaplan, 1988). Therefore, increased AST serum levels are not highly specific for cholestasis.

A second serum biomarker that is typically increased during cholestasis is the microsomal enzyme $\gamma$ glutamyltransferase (GGT). GGT also occurs as a membrane-bound form and shows, like ALP, a wide 
distribution not only in many tissues, including kidney, liver, pancreas and intestine (Hanigan \& Frierson, 1996), but also in circulating cells, such as leucocytes and lymphocytes (Grisk et al., 1993; Novogrodsky et al., 1976). In contrast, whereas isolated increased serum ALP concentrations can be found in some cholestatic diseases, isolated augmentation in GGT levels is less cholestasis-specific (EASL, 2009). Indeed, even though GGT is the most sensitive liver enzyme (Sheehan \& Haythorn, 1979), it lacks specificity, since serum levels are elevated in a variety of other diseases and conditions, such as renal insufficiency, hyperthyroidism, diabetes, pancreatitis, myocardial infarct, obesity and alcohol intake (Sotil \& Jensen, 2004; Whitfield, 2001). Hence, the main clinical relevance of serum GGT measurements lies in the possibility of excluding bone diseases causal for raised ALP levels, and to better comprehend increased ALP levels in growing children (Sotil \& Jensen, 2004).

$5^{\prime}$-nucleotidase ( $\left.5^{\prime}-\mathrm{NT}\right)$ is another enzyme whose serum levels increase upon cholestatic injury. Present in the liver as well as in other organs, it is mainly found at the surface of the cell plasma membrane (Sotil \& Jensen, 2004). As for GGT, serum concentrations of 5'-NT are independent from bone diseases, and, in contrast to ALP levels, pregnancy and childhood are no significant confounders (Dixon \& Purdom, 1954; Singh, 2013). However, human clinical laboratory use of this biomarker is seldom due to unclear advantages over combined ALP and GGT evaluations in hepatobiliary diseases (Smith et al. 2013).

A non-enzymatic biomarker that can be easily assessed in the blood is bilirubin. Unconjugated or indirect bilirubin is a pigmented degradation product from hemoglobin, derived from the lysis of aged red blood cells. This water-insoluble form circulates in the blood bound to albumin to be transported to the liver. Once reaching the liver, bilirubin is released from albumin and conjugated with glucuronic acid to obtain water-soluble conjugated (direct) bilirubin, which can then be excreted at the canalicular membrane into the bile duct and stored in the gall bladder. Cholestatic conditions, such as bile duct obstruction, can cause increased amounts of conjugated bilirubin in hepatocytes, followed by regurgitation of the latter into the blood, a process taking place in prolonged or severe cholestatic circumstances (Ramaiah, 2007; Shah \& John, 2018). Consequently, serum conjugated hyperbilirubinemia is an indicator of cholestasis, albeit in a more advanced disease stage (EASL, 2009; Pollock \& Minuk, 2017). In clinical settings, total and (un)conjugated bilirubin concentrations can be 
obtained, allowing for more insight in the underlying mechanistic basis of the cholestatic injury (Ramaiah, 2007).

Although subject for debate, the quantitative limits requiring further work up in suspicion of cholestasis are fixed at concentrations 1.5 times above the upper limit of normal (ULN) for serum ALP and 3 times above the ULN for serum GGT (EASL, 2009; Lu et al., 2016). However, these values must rather be interpreted as guidelines than rigid cut-offs, since distinct values have been established for specific cholestatic diseases (EASL, 2009; Lu et al., 2016; Singh, 2013). In addition, despite ALP and GGT being early biomarkers of cholestasis, often even elevated in asymptomatic patients, absence of altered levels in symptomatic patients is not unusual (EASL, 2009). In these cases, clinical judgement should prioritize in diagnostic work-up. Furthermore, depending on the type of cholestatic pathology, other clinical chemistry biomarkers can or must be included for diagnosis as well. In this regard, ALT can be of diagnostic help in detection of PBC and IgG4 positivity is in the vast majority of cases required for confirmation of IgG4-associated cholangitis (EASL, 2009; Kamisawa et al., 2019; Lu et al., 2016). In some conditions, like DIC, a combination of several clinical parameters proves advantageous to distinguish between other forms of liver injury (Chatterjee \& Annaert, 2018; EASL, 2009).

It must be clear that none of the aforementioned clinical chemistry biomarkers is truly liver-specific and each one of them bears its own pitfalls, the most important probably being the alterations in a variety of pathologies and conditions. Nevertheless, combination of multiple parameters can, at least in part, overcome this problem. Table 1 gives an overview of clinical chemistry biomarkers used in clinical settings for differential diagnosis of the most common cholestatic liver diseases.

\subsubsection{Histopathological biomarkers}

When suspecting cholestasis and clinical physical and chemistry biomarkers do not allow for clear diagnosis or represent atypical features, histopathological assessment following liver biopsy might be considered (EASL, 2009; Tan \& Goodman, 2018). The collected liver tissue is analyzed by a histopathologist, in order to recognize certain morphological alterations and patterns typically found in cholestasis and thus representing histopathological biomarkers. 
The main goal is to exclude intrahepatic from extrahepatic cholestasis, with specific attention for mechanic obstructions, since therapeutic treatment and prognosis highly differ for both types of cholestasis (Lefkowitch, 2004). An important parameter to be assessed during this process is the accumulation of bile salts (Gasmi \& Kleiner, 2020). Their location is informative not only regarding the distinction between intrahepatic and extrahepatic cholestasis, but also regarding the type of cholestasis. In this respect, accumulation of bile salts in periportal hepatocytes is typically seen in chronic cholestasis (Gasmi \& Kleiner, 2020; Lefkowitch, 2004). In line with this, some morphological patterns portray general features observed in cholestasis, whereas others can be indicative for a precise type of cholestasis. Thus, cholestasis-induced alterations predominate in the centrilobular region or acinar zone 3 independent from the type of cholestatic disease (Lefkowitch, 2004), whereas bile duct epithelial cell damage is a typical feature observed in early stage PBC (Tan \& Goodman, 2018).

Although highly informative, especially in cases of uncertainty, liver biopsies are not considered the preferred method for standard evaluation and confirmation of cholestatic diseases due to several limitations. The most common route for obtaining a liver specimen is percutaneously, which is not always possible, like in obese patients (Rockey et al., 2009). Alternative methods include laparoscopic, transvenous or plugged biopsy (Rockey et al., 2009). Regardless of the route used, performing a liver biopsy is an invasive procedure, frequently associated with complications and in rare cases death (Rockey et al., 2009; Tapper \& Lok, 2017). Once the sample is obtained, evaluation by a histopathologist takes place, which is subjective in nature, and high inter-operator and intra-operator differences have been reported (The French METAVIR Cooperative Study Group, 1994). Furthermore, sampling variability is a major limitation of liver biopsies. Cholestatic injury is not necessarily uniformly distributed throughout the entire liver and different liver zones can present with varying disease stages as well. Consequently, the spatiotemporal information regarding the cholestatic disease is dependent on the liver specimen analyzed (Jansen et al., 2017). Therefore, the collected biopsy should measure sufficient dimensions, and an inclusion of at least 10 portal fields has been suggested (EASL, 2009; Rockey et al., 2009; Tapper \& Lok, 2017). Despite the disadvantages, histopathological assessment of the liver remains necessary for diagnosis of some specific cholestatic diseases, such as small-duct PSC and antimitochondrial antibody-negative PBC (Tapper \& Lok, 2017). 


\subsection{Molecular biomarkers}

\subsubsection{Genetic biomarkers}

Genomics, the study of the genome in a wide sense, including structure, function and interaction of genes, has substantially contributed to identifying genetic causes and risk factors in cholestasis. In this regard, genome-wide association studies (GWAS), i.e. large-scale hypothesis-free studies in which whole genomes of cases versus controls are analyzed in order to associate altered genes with the clinical phenotype, together with next-generation sequencing (NGS), have provided a tremendous amount of genes involved in a variety of cholestatic diseases. In this light, 6 types of PFIC, each one characterized by a distinct clinical presentation, are currently known, with classification into the respective subtypes depending on the mutated gene (Reichert et al., 2018). Hence, in these monogenic diseases, typified by a clear genotype-to-phenotype association, the affected gene can serve as a genetic biomarker. Practically, the patient's DNA is tested against a gene panel, which includes several genes known to be mutated in specific cholestatic diseases, allowing for diagnosis and adequate treatment. Table 2 displays the currently existing genetic cholestasis testing panel, together with the associated disease upon mutation.

Monogenic liver diseases represent only a small fraction of liver diseases and given the multifaceted functions of the liver, it may not be surprising that the vast majority of cholestatic diseases encompass multiple affected genes (Krawczyk et al., 2010; Reichert et al., 2018). These polygenic diseases are presumed to be of multifactorial cause, in the sense that disease onset is dependent on higher-order interactions of multiple susceptibility genes and environmental influences (Cordell, 2009; Krawczyk et al., 2010; Zondervan \& Cardon, 2004). The proportional contribution of genetic and environmental factors to the pathogenesis is overly complex to unravel, but seemingly varies across diseases. Thus, the $\mathrm{D} 19 \mathrm{H}$ variant in the ABCG8 gene, which encodes the hepatocanalicular cholesterol hemitransporter, is the major risk factor for gallstone development (Buch et al., 2007). In a large-scale Swedish study, 21\% of twins with gallstones were carrier of at least one D19H allele (Katsika et al., 2010). This indicates a major contribution of 1 gene variant, but also highlights the importance of other environmental factors, 
which is even more underlined by the fact that the $\mathrm{D} 19 \mathrm{H}$ variant was present in $9 \%$ of non-affected individuals as well (Katsika et al., 2010; Stokes et al., 2011).

In many other cholestatic pathologies, unravelling the specific genetic contribution is an even more complicated task. A plethora of genetic polymorphisms has been associated with the autoimmune diseases PBC (Joshita et al., 2018) and PSC (Jiang \& Karlsen, 2017), with a significant number occurring on the genetic region coding for the human leucocyte antigen (HLA) complex, which is essential in regulation of immunity. However, the HLA region is highly polymorphic and many of the identified HLA risk loci in PBC and PSC have been associated with other autoimmune and immunemediated disorders (Karlsen et al., 2015; Liu et al., 2013; Trivedi \& Hirschfield, 2016). Accordingly, presence of these genetic risk factors rather implies global susceptibility for (auto)immune diseases than for the specific disease per se (Karlsen et al., 2015; Karlsen \& Chung, 2015). Furthermore, only 10\% of PBC (Galoosian et al., 2020) and PSC (Folseraas et al., 2015) patients carry identified susceptibility genes, indicating an important contribution of environmental factors in pathogenesis and possibly other yet unidentified rare variants (Joshita et al., 2018; Reichert et al., 2018).

It must be clear that altered genes can serve as valuable biomarkers in monogenic liver diseases, whereas diagnosis based on solely genetic biomarkers is less straightforward in polygenic complex diseases (Karlsen et al., 2015; Müllenbach \& Lammert, 2011). Furthermore, in case of the latter, presence of a genetic risk factor does not necessarily imply ultimate development of the disease, but must be considered as a status of predisposition (Hirschfield et al., 2013; Müllenbach \& Lammert, 2011; Reichert et al., 2018). In addition, identifying genetic risk factors eventually leading to cholestatic insult is extremely difficult due to the complexity and multifactorial causes of cholestasis. For this reason, expanded knowledge regarding cholestatic disease development is required to fully explore the potential of genetic biomarkers (Hirschfield et al., 2013; Müllenbach \& Lammert, 2011).

\subsubsection{Epigenetic biomarkers}

Epigenetics refers to the study of heritable alterations in the genome without changes in the primary DNA sequence (Waddington, 2012). Indeed, the ultimate transcriptional output of the cell DNA depends on a variety of non-genetic molecular pathways with as major mechanisms DNA methylation, histone 
modifications and subsequent chromatin remodeling, and regulation by non-coding RNAs (Al Aboud \& Jialal, 2018; Hardy \& Mann, 2016; Li et al., 2014). Non-coding RNAs can be divided in long noncoding RNAs and short non-coding RNAs, with microRNAs (miRNAs), i.e. approximately 22 nucleotide long RNA molecules that bind mRNA through complementary base-pairing, being the most extensively studied and characterized (Li et al., 2014; Wang et al., 2012). It is noteworthy that miRNAs play an important role in liver development and as an expected consequence a variety of miRNAs have been associated with different stages of many chronic liver diseases (Wang et al., 2012).

The epigenome contributes considerably to the ultimate phenotype of a cell and not surprisingly the study of the epigenetic pattern and its alterations is gaining interest as a source of useful biomarkers in disease (García-Giménez et al., 2017). The major advantage of epigenetic biomarkers is that the contribution of non-genetic factors, such as age, diet, microbiome and exercise, is incorporated, since epigenetic regulations strongly respond to these environmental triggers (García-Giménez et al., 2017; Hardy \& Mann, 2016). This is reflected in the bulk of the recently discovered potential epigenetic biomarkers for cholestatic conditions, of which a vast majority is linked with bile acid metabolism, the key player in developing cholestatic conditions, known to be highly dependent on environmental factors (Smith et al., 2013). In this regard, trimethylation of histone H3 lysine 4 (H3K4) is critical for the activation of several bile acid transporter genes by nuclear receptors and is downregulated in cholestasis, rendering the trimethylated $\mathrm{H} 3 \mathrm{~K} 4$ a possible epigenetic biomarker for cholestasis (Ananthanarayanan et al., 2011). MicroRNA-210 (miR-210) levels are increased in cholestatic mice and binding to their target causes decreased bile salt export pump (BSEP) levels and consequently disturbed bile acid metabolism (Kim et al., 2020). Interestingly, elevated hepatic miR-210 levels are also found in PBC patients, introducing possibilities for this small non-coding RNA as biomarker and potential therapeutic target in cholestatic diseases (Kim et al., 2020). Another non-coding RNA that gained interest during the last decade is the long non-coding RNA H19 (Li \& Liu, 2020). Liver H19 levels are elevated in cholestatic mice and human and although bile acid accumulation is suggested, the exact mechanism behind these observations remains to be elucidated (Li \& Liu, 2020; Xiao et al., 2019; Zhang et al., 2016).

This highlights a significant complication of epigenetic biomarkers, namely a profound understanding of the underlying epigenetic regulatory mechanisms, which are highly dynamic and complex, in healthy 
as well as cholestatic conditions is required to fully exploit the potential of these new biomarkers (García-Giménez et al., 2017). At the same time, the dynamicity and adaptational capacity to environmental cues of these regulation mechanisms encompass the main advantage of epigenetic biomarkers, namely that they allow to explain interinduvidual variability and pave the way to precision medicine (García-Giménez et al., 2017; Hardy \& Mann, 2016).

\subsubsection{Transcriptomic biomarkers}

The transcriptome is the complete collection of all RNA molecules in a cell or cell population. This includes coding mRNA, which is translated into proteins, but also non-coding RNA, such as tRNA, rRNA and miRNA. In a wide sense, transcriptomics involves the study of both categories of RNA, nevertheless generally it is mostly applied to mRNA (Blumenberg, 2019; European Medicines Agency, 2019). The earliest technique developed to study (whole) transcriptomes is the microarray, which uses multiple known nucleic acid sequences attached to solid spots to act as detecting probes upon hybridization with a complementary sequence (Schena et al., 1995). Whereas this method, quick in generating and processing data, allows for quantification and detection of known transcripts, it is not applicable for discovering novel sequences (Yang et al., 2020). The more recent RNA sequencing method, an application of NGS, overcomes this drawback and moreover is more sensitive and resolutive (Mortazavi et al., 2008; Wang et al., 2009; Yang et al., 2020).

The characteristics inherent to each technique have defined their applicability in specific research domains. Microarrays have proven a valuable tool to study alterations in gene expression profiles in the field of drug development and toxicity testing of known compounds (Blomme et al., 2009; Yang et al., 2020). Regarding cholestasis, a certain number of studies have assessed transcription profiles in DIC in vitro, in vivo and ex vivo, and allowed for identification of altered transcribed genes or gene sets upon application of certain cholestatic drugs (de Longueville et al., 2003; Kienhuis et al., 2013; Rodrigues et al., 2018; Szalowska et al., 2013; Van den Hof et al., 2017). Interestingly, cluster analysis of unique gene expression profiles generated by several hepatotoxicants demonstrated that drugs known to cause cholestatic injury were categorizable in the same cluster, proposing a future role for these transcripts as biomarkers in toxicological studies (de Longueville et al., 2003). The RNA sequencing technology on 
the other hand is highly appreciated as high-throughput screening technique for identification of novel altered transcripts induced by drugs (Sun et al., 2019; Yang et al., 2020).

Transcriptomics have been proven useful in other domains than solely drug induced cholestasis, and a plethora of altered transcription profiles has been associated with other cholestatic conditions, such as PBC (Baba et al., 2006; Ostrowski et al., 2019), PSC (Ostrowski et al., 2019; Tabibian et al., 2014) and gallstones (Li et al., 2014; Yang et al., 2015). However, these discovered altered gene signatures currently rather encourage to unravel the underlying pathological mechanism than being usable biomarkers, since many of them lack clearly described functions and rather support or provide hypotheses regarding disease pathways (Blumenberg, 2019; Ostrowski et al., 2019; Pertea, 2012). Nevertheless, after future research will have shed more light on these compelling questions, transcriptomic biomarkers may be of great value as clinical biomarkers, since they allow for information of a precise tissue at a specific time point of the disease (Yang et al., 2020). Furthermore, alterations in transcripts likely occur early in disease, before clinical phenotypical manifestations or detectable changes in classical chemistry biomarkers. This renders transcriptomic biomarkers a promising tool for early detection or even prediction of cholestatic liver diseases (Blomme et al., 2009).

\subsubsection{Proteomic biomarkers}

Even though transcriptomics has great potential in providing novel clinical applicable biomarkers for cholestatic diseases, it also suffers from some drawbacks. mRNA levels do not correspond very well with their respective protein concentrations (Vogel \& Marcotte, 2012), rendering mRNA analysis somehow difficult to interpret, since it is the transcribed protein that is biologically active and thus representative for disease status. Moreover, this biologically active state of the protein is orchestrated by post-translational modifications, such as acetylation, glycosylation and phosphorylation, all processes that are undetectable in mRNA levels or sequences (Krishna \& Wold, 2006). In addition, one mRNA sequence can give rise to a variety of proteins due to protein polymorphisms or alternative splicing (Barrier \& Mirkes, 2005). Proteomics, the analysis of all translated proteins of a cell or tissue, including their functions and interactions, overcomes these inconveniences. 
The procedure of proteomic biomarker discovery starts with depletion of abundant proteins in the sample, usually plasma or serum, in order to detect and/or quantify low abundant proteins (Nallagangula et al., 2018). After depletion, proteins are separated by two-dimensional gel electrophoresis (2-DE) and visualized by staining techniques (Görg et al., 2004). Significant protein spots are excised out of the gel, digested and identified by mass spectrometry (MS) techniques (Mas et al., 2009; Nallagangula et al., 2018). MS equipment uses ionization to measure protein properties. Once ionized, the proteins are channeled through one (MS) mass analyzer in order to verify the mass of the protein, or two (MS/MS) mass analyzers to determine the amino acid sequence of the protein (Mas et al., 2009). 2-DE however is unsuited for high-throughput and has low sensitivity and reproducibility (Veenstra, 2007). The combination of liquid chromatography (LC) with MS, or LC-MS, also referred to as shotgun proteomics, overcomes these problems (Hu et al., 2007). Protein-arrays are used in some cases as well, however, the lack of well-established arrays limits their utility in biomarker discovery (Mas et al., 2009; Niu et al., 2018).

Although promising, currently the amount of studies relying on proteomics to assess (novel) biomarkers in liver disease is sparse, and the majority of them has been focused on hepatocellular carcinoma (Niu et al., 2018; Parent \& Beretta, 2005). The few studies investigating cholestasis associated diseases by proteomic techniques mainly concentrated on the bile proteome, given the evident role of bile in cholestatic conditions (Farina et al., 2014). The advantage of the use of this biological fluid lies in the fact that pathology associated protein concentrations are higher in fluids surrounding the lesions than in plasma or serum, where they will become highly diluted and probably even undetectable (Teng et al., 2010). On the other hand, collecting bile samples is an invasive procedure and bile acids and other molecules present may interfere with bile proteins during the analytical procedure (Teng et al., 2010). Nevertheless, studies relying on human bile samples for proteomic purposes have been proven promising. In this regard, it has been demonstrated that cholangiocarcinoma can be distinguished from PSC patients based on bile protein patterns (Lankisch et al., 2011). Interestingly, in an independent prospective study, some of these bile proteins were found to be significantly elevated in cholangiocarcinoma compared with PSC patients (Navaneethan et al., 2015). This was later on expanded by analyzing blood and urine as sample matrix. Whereas urine seemed to be a valid diagnostic tool to 
separate cholangiocarcinoma from PSC conditions, blood was unworkable, due to the marked range between low and high abundancy proteins (Metzger et al., 2013). However, it was concluded that a combination of bile and urine sample analysis would be necessary to achieve increased specificity (Metzger et al., 2013).

Despite some limited yet encouraging results, potential proteomic biomarkers are not entirely validated for use in clinical settings for diagnosis or prognosis of cholestatic pathologies (Niu et al., 2018). The technological advances in the last decades allow for high-throughput identification of novel proteins altered in liver disease, but the lack of knowledge of their functions and interactions in normal conditions hinders their utility as biomarkers (Barbhuiya et al., 2011; Niu et al., 2018; Parent \& Beretta, 2005). In addition, the complete human proteome remains to be elucidated and standardized protocols for sample preparation or data analysis to be developed. The Human Liver Proteome Project, as part of the Human Proteome Organization, aims at resolving the aforementioned issues and plays an essential role in exploiting the full potential of proteomic biomarkers in cholestatic liver diseases (He, 2005; Tyers \& Mann, 2003).

\subsubsection{Metabolomic biomarkers}

Of all 'omics' technologies, metabolomics is one of the latest to have gained research interest. It can best be described as the analysis of all metabolites or low molecular weight intermediates, which are context-dependent, in a biological sample (Griffin \& Shockcor, 2004; Oliver, 2002). The term 'metabonomics' was first defined by Nicholson and colleagues as 'the quantitative measurement of the dynamic multiparametric metabolic response of living systems to pathophysiological stimuli or genetic modification' (Nicholson et al., 1999). Both terms are frequently used interchangeably, since the difference in definition is somewhat ambiguous and currently their differentiation is proposed to rather rely on differences in analytical techniques (Beyoğlu \& Idle, 2020; Nicholson \& Lindon, 2008). For the sake of simplicity, the term metabolomics will be used hereafter.

The main techniques used in metabolomics are nuclear magnetic resonance (NMR) spectroscopy and MS. The major advantage of NMR spectroscopy is that biological samples do not require preanalytical treatment (Nicholson \& Lindon, 2008; Sinclair \& Dudley, 2019). This renders this technique highly 
appreciated for in vivo and in situ studies (Yu et al., 2017). Even though NMR spectroscopy knows a relative simple workflow and provides highly reproducible results, it lacks sensitivity (Griffin \& Shockcor, 2004; Sinclair \& Dudley, 2019). MS largely overcomes this issue, and is furthermore more suitable for high throughput profiling of metabolites (Sinclair \& Dudley, 2019). The downside of this technique however is the necessity for separation of biological fluids prior to analysis (Beyoğlu \& Idle, 2020; Nicholson \& Lindon, 2008). The most frequently used separation techniques are LC and gas chromatography (GC), rendering metabolites liquid and volatile respectively (Nicholson \& Lindon, 2008; Sinclair \& Dudley, 2019).

As metabolites represent the end product of biological pathways, they can be considered a recapitulation all foregoing upstream information, including genetic, epigenetic, transcriptomic and proteomic data (Gahlaut et al., 2013; Griffin \& Shockcor, 2004). This renders measurement of metabolite concentrations highly useful in biological pathway identification, since they designate the net result of all preceding steps in the studied biological system, in contrast to protein or mRNA concentrations (Griffin \& Shockcor, 2004). Furthermore, changes in metabolite patterns occur rapidly and provide information regarding disturbed known pathways, allowing for early detection of disease (Griffin \& Shockcor, 2004; Nicholson \& Lindon, 2008). It may not be surprising that the liver, as principal metabolically active tissue, and the hepatic metabolome have gained much interest in the field of metabolomics. Here as well, many investigations have been aiming at discovering biomarkers in hepatocellular carcinoma. In this regard, the research for metabolomic biomarkers in cholestatic conditions, as possible premalignant stage of hepatocellular carcinoma, has started to grow in this last decade (Beyoğlu \& Idle, 2020).

Currently, the majority of studies has been relying on cholestatic murine models to detect associated altered metabolite levels in liver, urine, serum or plasma, with a main focus on bile acids (Aoki et al., 2011; Chen et al., 2016; Cho et al., 2010; Fu et al., 2019; Long et al., 2015; Yamazaki et al., 2013; Yang et al., 2018). Each study provided novel discovered metabolites whose concentrations were altered in cholestatic conditions. However, the limited number of studies and the use of different experimental models renders conclusions regarding definite valid metabolomic cholestatic biomarkers premature. 
Efforts have also been made to allow for metabolomic differentiation between several (cholestatic) liver diseases, such as between autoimmune hepatitis and PBC (Lian et al., 2015), PBC and PSC (Bell et al., 2015; Trottier et al., 2012), PBC and Celiac disease (Vignoli et al., 2019) and ICP and asymptomatic hypercholanemia of pregnancy (Chen et al., 2019). In this regard, evidence is growing that PBC and PSC could be distinguished based on metabolic primary and secondary bile acid patterns and concentrations (Bell et al., 2015; Lian et al., 2015; Tang et al., 2015; Trottier et al., 2012).

Although metabolomic biomarkers are highly valued in cholestasis and in liver pathology in general, the field of metabolomics is still in its infancy. Due to the novelty of this research area, the current available techniques and analyses are not entirely optimized for their purpose neither globally standardized, complicating data processing and comparison (Gahlaut et al., 2013; Yu et al., 2017). In addition, the complete human metabolome comprises a tremendous amount of molecules, which are far from being all identified (Wishart et al., 2018). So far, discovered metabolites in cholestatic diseases are to be regarded as potential biomarkers, but should foremost be used as a tool to shed more light on disease mechanisms (Beyoğlu \& Idle, 2013; Nicholson \& Lindon, 2008).

\section{Conclusions and future perspectives}

Cholestasis is a relative mild pathology, but when left untreated can develop into life threatening conditions. Initial suspicion of cholestasis is raised based on patients' clinical presentation, yet given the asymptomatic character of the disease, the start of clinical work-up does not unfrequently take place at a more advanced disease stage (EASL, 2009; Lu et al., 2016). Traditional clinical serum biomarkers are currently the gold standard in the detection of cholestasis, and are frequently combined with physical and histopathological biomarkers (EASL, 2009; Lu et al., 2016). However, even when combining several traditional biomarkers, the required specificity, sensitivity and accuracy is not always achieved, and false negative results persist (Onofrio \& Hirschfield, 2020; Ozer et al., 2008). In addition, given the possible severe outcomes of cholestasis and the subsequent financial losses from an economic and patient point of view, there is an urging need for biomarkers capable of prognosis of the disease and 
determining disease severity (Pirola \& Sookoian, 2018; Schork, 2015; Vinken et al., 2013). With the ascent of 'omics', a tremendous amount of novel possible molecular biomarkers has been discovered, in view of fulfilling the demanding criteria of biomarkers. However, for the vast majority of these newly discovered potential biomarkers, the clinical relevance remains ambiguous, mainly due to a lagging behind of adapted software and standardized protocols for data analysis, as well as insufficient knowledge of existing molecular pathways (Hardy \& Mann, 2016; Matthews et al., 2016; Noor, 2015). In addition, unraveling their precise role in cholestatic conditions, and consequently estimating the possibility for use as biomarker, is extremely puzzling, since each of these molecules intervenes at a specific point in the pathological pathway, influencing and being influenced by upstream as well as downstream events and molecules. The utility of these novel 'omics' technologies and discoveries therefore currently rather lies in filling the gaps in our present understanding of biological and pathological molecular pathways by integrating and combining multiple 'omics' studies (Matthews et al., 2016; Noor, 2015; Yang et al., 2020).

An adverse outcome pathway (AOP) has been developed for cholestatic liver injury (Vinken et al., 2013). An AOP is a conceptual construct that links an initial molecular initiating event with an adverse outcome through intermediate key events, hence being of high value in discerning molecular disease pathways (Villeneuve et al., 2014). The AOP for cholestatic liver injury focusses on inhibition of the BSEP as initiating event, resulting in increased liver bile acid accumulation (Vinken et al., 2013). This triggers two cellular responses, namely an initial deteriorative response, characterized by mitochondrial impairment, inflammation, oxidative stress and cell death, and an adaptive response, aiming at counteracting the increased bile acid concentration, by inducing transcriptional changes (Vinken et al., 2013). Recently, the robustness of the developed AOP has been tested by transcriptional analysis of genes involved in both responses (Gijbels et al., 2020). In compliance with the established AOP, the OATP1B1 and the SLC10A1 genes were significantly upregulated, leading to the conclusion that these genes could be potential early biomarkers of cholestatic disease (Table 3) (Gijbels et al., 2020). This highlights the value of AOPs in unravelling molecular disease mechanisms as well as their important contribution to biomarker discovery. 
In the near future, different strategies and optimizations will be essential for translation of obtained data into clinical practice and management of cholestasis. First of all, there is insufficient reproducibility between results, mainly due to a lack of standardization in analytical methods and a concrete definition of analytical variables in laboratory and clinical set-ups, despite great technical advances (Matthews et al., 2016; Strimbu \& Tavel, 2010b). Efforts must be put on developing and validating standardized bioinformatic tools as well as open-access databases for cataloging novel discoveries (Matthews et al., 2016; Noor, 2015). In this regard, several databases have originated the last decade, such as the Human Protein Atlas and the Human Metabolome Database. Second, increased collaboration must occur between key players in biomarker discovery, validation and implementation, namely industry and academia (Matthews et al., 2016). Whereas in general the former excels in providing tremendous amounts of potential biomarkers generated by use of high-throughput sophisticated technology, the latter furnishes indispensable knowledge by time-consuming research (Babrak et al., 2019). Both aspects are complementary though and their collaboration will speed up and ameliorate the research for biomarkers in cholestasis and many other pathologies (Matthews et al., 2016). Third, with the increased interest in precision medicine, interpersonal and intrapersonal variability should be taken into account when assessing potential biomarkers, and this especially during clinical trials (Babrak et al., 2019; Schork, 2015). On the one hand, monitoring multiple biological parameters and 'omics' biomarkers of one single person can balance intrapersonal variability, hence augmenting the chance of establishing representative biomarkers, which is less probable when measuring so-called snapshots of clinical parameters (Babrak et al., 2019). On the other hand, an increased patient data availability by continuous monitoring of multiple parameters would allow to correct for interpersonal variability, subsequently aiding in a better patient stratification (Matthews et al., 2016; Schork, 2015). This would empower the creation of more homogenous patient groups, hence leading to more confident conclusions (Matthews et al., 2016; Schork, 2015).

The perfect future biomarker for cholestasis ideally should allow for more precise and faster diagnosis, but also prognosis of the disease. Furthermore, it should be non-invasive, rapidly assessable and easily quantifiable. Importantly, it should be interspecies extrapolatable and preferably accessible via highthroughput techniques (Marrer \& Dieterle, 2010; Ozer et al., 2008; Vinken et al., 2013). Of course, such 
demanding requirements bear considerable costs in terms of discovery, development, clinical studies and analytical validation (Babrak et al., 2019). It is however not expected that one single novel molecular biomarker will replace traditional clinical biomarkers, but rather they will be assessed together in order to obtain more qualitative, complete and reliable information (Noor, 2015). This holistic approach will bear fruit not only in diagnosis, treatment and prognosis of cholestasis but even in other complex diseases, especially with the upcoming era of personalized medicine (Babrak et al., 2019; Hirschfield et al., 2013; Noor, 2015).

\section{Acknowledgements}

This study was financially supported by the Fund for Scientific Research-Flanders (FWO Vlaanderen

Grants G009514N and G010214N), the Fundação de Amparo à Pesquisa do Estado de São Paulo (FAPESP-FWO Grant 18/10953-9), the University Hospital of the Vrije Universiteit Brussel-Belgium (Willy Gepts Fonds UZ-Brussel) and the Center for Alternatives to Animal Testing at Johns Hopkins University-USA (Grant 2018-13).

\section{References}

Accatino, L., Figueroa, C., Pizarro, M., \& Solís, N. (1995). Enhanced biliary excretion of canalicular membrane enzymes in estrogen-induced and obstructive cholestasis, and effects of different bile acids in the isolated perfused rat liver. Journal of Hepatology, 22(6), 658-670. https://doi.org/10.1016/0168-8278(95)80221-5

Al Aboud, N. M., \& Jialal, I. (2018). Genetics, Epigenetic Mechanism. In StatPearls. StatPearls Publishing. http://www.ncbi.nlm.nih.gov/pubmed/30422591

Ananthanarayanan, M., Li, Y., Surapureddi, S., Balasubramaniyan, N., Ahn, J., Goldstein, J. A., \& Suchy, F. J. (2011). Histone H3K4 trimethylation by MLL3 as part of ASCOM complex is critical for NR activation of bile acid transporter genes and is downregulated in cholestasis. 
American Journal of Physiology - Gastrointestinal and Liver Physiology, 300(5), G771. https://doi.org/10.1152/ajpgi.00499.2010

Aoki, M., Konya, Y., Takagaki, T., Umemura, K., Sogame, Y., Katsumata, T., \& Komuro, S. (2011). Metabolomic investigation of cholestasis in a rat model using ultra-performance liquid chromatography/tandem mass spectrometry. Rapid Communications in Mass Spectrometry, 25(13), 1847-1852. https://doi.org/10.1002/rcm.5072

Baba, N., Kobashi, H., Yamamoto, K., Terada, R., Suzuki, T., Hakoda, T., Okano, N., Shimada, N., Fujioka, S. I., Iwasaki, Y., \& Shiratori, Y. (2006). Gene expression profiling in biliary epithelial cells of primary biliary cirrhosis using laser capture microdissection and cDNA microarray. Translational Research, 148(3), 103-113. https://doi.org/10.1016/j.trsl.2006.04.007

Babrak, L. M., Menetski, J., Rebhan, M., Nisato, G., Zinggeler, M., Brasier, N., Baerenfaller, K., Brenzikofer, T., Baltzer, L., Vogler, C., Gschwind, L., Schneider, C., Streiff, F., Groenen, P. M. A., \& Miho, E. (2019). Traditional and Digital Biomarkers: Two Worlds Apart? Digital Biomarkers, 3(2), 92-102. https://doi.org/10.1159/000502000

Barbhuiya, M. A., Sahasrabuddhe, N. A., Pinto, S. M., Muthusamy, B., Singh, T. D., Nanjappa, V., Keerthikumar, S., Delanghe, B., Harsha, H. C., Chaerkady, R., Jalaj, V., Gupta, S., Shrivastav, B. R., Tiwari, P. K., \& Pandey, A. (2011). Comprehensive proteomic analysis of human bile. Proteomics, 11(23), 4443-4453. https://doi.org/10.1002/pmic.201100197

Barrier, M., \& Mirkes, P. E. (2005). Proteomics in developmental toxicology. In Reproductive Toxicology (Vol. 19, Issue 3, pp. 291-304). Elsevier Inc. https://doi.org/10.1016/j.reprotox.2004.09.001

Bell, L. N., Wulff, J., Comerford, M., Vuppalanchi, R., \& Chalasani, N. (2015). Serum metabolic signatures of primary biliary cirrhosis and primary sclerosing cholangitis. Liver International, 35(1), 263-274. https://doi.org/10.1111/liv.12680

Beyoğlu, D., \& Idle, J. R. (2020). Metabolomic and lipidomic biomarkers for premalignant liver disease diagnosis and therapy. In Metabolites (Vol. 10, Issue 2, p. 50). MDPI AG. https://doi.org/10.3390/metabo10020050

Beyoğlu, D., \& Idle, J. R. (2013). The metabolomic window into hepatobiliary disease. In Journal of 
Hepatology (Vol. 59, Issue 4, pp. 842-858). NIH Public Access.

https://doi.org/10.1016/j.jhep.2013.05.030

Blomme, E. A. G., Yang, Y., \& Waring, J. F. (2009). Use of toxicogenomics to understand mechanisms of drug-induced hepatotoxicity during drug discovery and development. In Toxicology Letters (Vol. 186, Issue 1, pp. 22-31). Elsevier. https://doi.org/10.1016/j.toxlet.2008.09.017

Blumenberg, M. (2019). Introductory Chapter: Transcriptome Analysis. In Transcriptome Analysis. IntechOpen. https://doi.org/10.5772/intechopen.85980

Boyde, T. R. C., \& Latner, A. L. (1962). Starch-gel Electrophoresis of Trans- aminases in HumanTissue Extracts and Sera. In Biochem. J (Vol. 82).

Buch, S., Schafmayer, C., Völzke, H., Becker, C., Franke, A., Von Eller-Eberstein, H., Kluck, C., Bässmann, I., Brosch, M., Lammert, F., Miquel, J. F., Nervi, F., Wittig, M., Rosskopf, D., Timm, B., Höll, C., Seeger, M., Elsharawy, A., Lu, T., ... Hampe, J. (2007). A genome-wide association scan identifies the hepatic cholesterol transporter ABCG8 as a susceptibility factor for human gallstone disease. Nature Genetics, 39(8), 995-999. https://doi.org/10.1038/ng2101

Cao, X., Gao, Y., Zhang, W., Xu, P., Fu, Q., Chen, C., Li, C., Yang, C., Ma, G., Qu, Y., Xu, M., \& Lu, L. (2015). Cholestasis morbidity rate in first-hospitalized patients with chronic liver disease in Shanghai. Chinese Journal of Hepatology, 23(8), 569-573. https://doi.org/10.3760/cma.j.issn.1007-3418.2015.08.003

Chatterjee, S., \& Annaert, P. (2018). Drug-induced Cholestasis: Mechanisms, Models, and Markers. Current Drug Metabolism, 19(10), 808-818. https://doi.org/10.2174/1389200219666180427165035

Chen, X., Zhang, X., Xu, B., Cui, Y., He, Y., Yang, T., Shao, Y., \& Ding, M. (2019). The urinary bile acid profiling analysis of asymptomatic hypercholanemia of pregnancy: A pseudo-targeted metabolomics study. Clinica Chimica Acta, 497, 67-75. https://doi.org/10.1016/j.cca.2019.07.002

Chen, Z., Zhu, Y., Zhao, Y., Ma, X., Niu, M., Wang, J., Su, H., Wang, R., Li, J., Liu, L., Wei, Z., Zhao, Q., Chen, H., \& Xiao, X. (2016). Serum Metabolomic Profiling in a Rat Model Reveals 
Protective Function of Paeoniflorin Against ANIT Induced Cholestasis. Phytotherapy Research, 30(4), 654-662. https://doi.org/10.1002/ptr.5575

Cho, J. Y., Matsubara, T., Kang, D. W., Ahn, S. H., Krausz, K. W., Idle, J. R., Luecke, H., \& Gonzalez, F. J. (2010). Urinary metabolomics in Fxr-null mice reveals activated adaptive metabolic pathways upon bile acid challenge. Journal of Lipid Research, 51(5), 1063-1074. https://doi.org/10.1194/jlr.M002923

Cieszanowski, A., Chomicka, D., Andrzejewska, M., Pruszyński, B., Pawlak, J., \& Mustafa, A. M. (2000). Imaging techniques in patients with biliary obstruction. Medical Science Monitor, 6(6), $1197-1202$.

Cordell, H. J. (2009). Detecting gene-gene interactions that underlie human diseases. In Nature Reviews Genetics (Vol. 10, Issue 6, pp. 392-404). Europe PMC Funders. https://doi.org/10.1038/nrg2579

Corpechot, C. (2016). Utility of Noninvasive Markers of Fibrosis in Cholestatic Liver Diseases. Clinics in Liver Disease, 20(1), 143-158. https://doi.org/10.1016/j.cld.2015.08.013

de Longueville, F., Atienzar, F. A., Marcq, L., Dufrane, S., Evrard, S., Wouters, L., Leroux, F., Bertholet, V., Gerin, B., Whomsley, R., Arnould, T., Remacle, J., \& Canning, M. (2003). Use of a low-density microarray for studying gene expression patterns induced by hepatotoxicants on primary cultures of rat hepatocytes. In Toxicological Sciences (Vol. 75, Issue 2, pp. 378-392). https://doi.org/10.1093/toxsci/kfg196

Deng, J. T., Hoylaerts, M. F., De Broe, M. E., \& Van Hoof, V. O. (1996). Hydrolysis of membranebound liver alkaline phosphatase by GPI-PLD requires bile salts. American Journal of Physiology - Gastrointestinal and Liver Physiology, 271(4 34-4), G655-63. https://doi.org/10.1152/ajpgi.1996.271.4.g655

Dixon, T. F., \& Purdom, M. (1954). Serum 5-nucleotidase. In J. clin. Path (Vol. 7).

EASL. (2009). European Association for the Study of the Liver Clinical Practice Guidelines: Management of cholestatic liver diseases. Journal of Hepatology, 51(2), 237-267. https://doi.org/10.1016/j.jhep.2009.04.009

European Association for the Study of the Liver. (2009). EASL Clinical Practice Guidelines: 
Management of cholestatic liver diseases. Journal of Hepatology, 51(2), 237-267.

https://doi.org/10.1016/j.jhep.2009.04.009

European Medicines Agency. (2019). Genomics Genetics , Transcriptomics and Epigenetics Subgroup report.

Farina, A., Delhaye, M., Lescuyer, P., \& Dumonceau, J. M. (2014). Bile proteome in health and disease. Comprehensive Physiology, 4(1), 91-108. https://doi.org/10.1002/cphy.c130016

Folseraas, T., Liaskou, E., Anderson, C. A., \& Karlsen, T. H. (2015). Genetics in PSC: What Do the "Risk Genes" Teach Us? Clinical Reviews in Allergy and Immunology, 48(2-3), 154-164. https://doi.org/10.1007/s12016-014-8417-z

Frulio, N., \& Trillaud, H. (2013). Ultrasound elastography in liver. In Diagnostic and Interventional Imaging (Vol. 94, Issue 5, pp. 515-534). Elsevier Masson SAS. https://doi.org/10.1016/j.diii.2013.02.005

Fu, K., Wang, C., Gao, Y., Fan, S., Zhang, H., Sun, J., Jiang, Y., Liu, C., Guan, L., Liu, J., Huang, M., $\&$ Bi, H. (2019). Metabolomics and lipidomics reveal the effect of hepatic Vps33b deficiency on bile acids and lipids metabolism. Frontiers in Pharmacology, 10, 276. https://doi.org/10.3389/fphar.2019.00276

Gahlaut, A., Vikas, Dahiya, M., Gothwal, A., Kulharia, M., Chhillar, A. K., Hooda, V., \& Dabur, R. (2013). Proteomics \& metabolomics: Mapping biochemical regulations. In Drug Invention Today (Vol. 5, Issue 4, pp. 321-326). No longer published by Elsevier. https://doi.org/10.1016/j.dit.2013.08.007

Galoosian, A., Hanlon, C., Zhang, J., Holt, E. W., \& Yimam, K. K. (2020). Clinical Updates in Primary Biliary Cholangitis: Trends, Epidemiology, Diagnostics, and New Therapeutic Approaches. Journal of Clinical and Translational Hepatology, X(X), 1-12. https://doi.org/10.14218/jcth.2019.00049

García-Giménez, J. L., Seco-Cervera, M., Tollefsbol, T. O., Romá-Mateo, C., Peiró-Chova, L., Lapunzina, P., \& Pallardó, F. V. (2017). Epigenetic biomarkers: Current strategies and future challenges for their use in the clinical laboratory. In Critical Reviews in Clinical Laboratory Sciences (Vol. 54, Issues 7-8, pp. 529-550). https://doi.org/10.1080/10408363.2017.1410520 
Gasmi, B., \& Kleiner, D. E. (2020). Liver Histology: Diagnostic and Prognostic Features. Clinics in Liver Disease, 24(1), 61-74. https://doi.org/10.1016/j.cld.2019.09.004

Gijbels, E., Vilas-Boas, V., Annaert, P., Vanhaecke, T., Devisscher, L., \& Vinken, M. (2020). Robustness testing and optimization of an adverse outcome pathway on cholestatic liver injury. Archives of Toxicology, 94(4), 1151-1172. https://doi.org/10.1007/s00204-020-02691-9

Görg, A., Weiss, W., \& Dunn, M. J. (2004). Current two-dimensional electrophoresis technology for proteomics. PROTEOMICS, 4(12), 3665-3685. https://doi.org/10.1002/pmic.200401031

Griffin, J. L., \& Shockcor, J. P. (2004). Metabolic profiles of cancer cells. Nature Reviews Cancer, 4(7), 551-561. https://doi.org/10.1038/nrc1390

Grisk, O., Küster, U., \& Ansorge, S. (1993). The activity of $\gamma$-glutamyl transpeptidase ( $\gamma$-gt) in populations of mononuclear cells from human peripheral blood. Biological Chemistry HoppeSeyler, 374(1-6), 287-290. https://doi.org/10.1515/bchm3.1993.374.1-6.287

Hall, P., \& Cash, J. (2012). What is the real function of the Liver "Function" tests? Ulster Medical Journal, 81(1), 30-36. www.ums.ac.uk

Hanigan, M. H., \& Frierson, H. F. (1996). Immunohistochemical detection of $\gamma$-glutamyl transpeptidase in normal human tissue. Journal of Histochemistry and Cytochemistry, 44(10), 1101-1108. https://doi.org/10.1177/44.10.8813074

Hardy, T., \& Mann, D. A. (2016). Epigenetics in liver disease: From biology to therapeutics. Gut, 65(11), 1895-1905. https://doi.org/10.1136/gutjnl-2015-311292

Hatoff, D. E., \& Hardison, W. G. M. (1982). Bile Acid-Dependent Secretion of Alkaline Phosphatase in Rat Bile. Hepatology, 2(4), 433S-439S. https://doi.org/10.1002/hep.1840020407

He, F. (2005). Human liver proteome project: Plan, progress, and perspectives. Molecular and Cellular Proteomics, 4(12), 1841-1848. https://doi.org/10.1074/mcp.R500013-MCP200

Hirschfield, G. M., Chapman, R. W., Karlsen, T. H., Lammert, F., Lazaridis, K. N., \& Mason, A. L. (2013). The genetics of complex cholestatic disorders. In Gastroenterology (Vol. 144, Issue 7, pp. 1357-1374). W.B. Saunders. https://doi.org/10.1053/j.gastro.2013.03.053

Hu, L., Ye, M., Jiang, X., Feng, S., \& Zou, H. (2007). Advances in hyphenated analytical techniques for shotgun proteome and peptidome analysis-A review. In Analytica Chimica Acta (Vol. 598, 
Issue 2, pp. 193-204). Elsevier. https://doi.org/10.1016/j.aca.2007.07.046

Jansen, P. L. M., Ghallab, A., Vartak, N., Reif, R., Schaap, F. G., Hampe, J., \& Hengstler, J. G.

(2017). The ascending pathophysiology of cholestatic liver disease. In Hepatology (Vol. 65, Issue 2, pp. 722-738). John Wiley and Sons Inc. https://doi.org/10.1002/hep.28965

Jiang, X., \& Karlsen, T. H. (2017). Genetics of primary sclerosing cholangitis and pathophysiological implications. In Nature Reviews Gastroenterology and Hepatology (Vol. 14, Issue 5, pp. 279295). Nature Publishing Group. https://doi.org/10.1038/nrgastro.2016.154

Joshita, S., Umemura, T., Tanaka, E., \& Ota, M. (2018). Genetics and epigenetics in the pathogenesis of primary biliary cholangitis. In Clinical Journal of Gastroenterology (Vol. 11, Issue 1, pp. 1118). Springer Tokyo. https://doi.org/10.1007/s12328-017-0799-z

Jüngst, C., \& Lammert, F. (2013). Cholestatic liver disease. Digestive Diseases, 31(1), 152-154. https://doi.org/10.1159/000347210

Kamisawa, T., Nakazawa, T., Tazuma, S., Zen, Y., Tanaka, A., Ohara, H., Muraki, T., Inui, K., Inoue, D., Nishino, T., Naitoh, I., Itoi, T., Notohara, K., Kanno, A., Kubota, K., Hirano, K., Isayama, H., Shimizu, K., Tsuyuguchi, T., ... Yoshida, M. (2019). Clinical practice guidelines for IgG4related sclerosing cholangitis. Journal of Hepato-Biliary-Pancreatic Sciences, 26(1), 9-42. https://doi.org/10.1002/jhbp.596

Karlsen, T. H., \& Chung, B. K. (2015). Genetic Risk and the Development of Autoimmune Liver Disease. Digestive Diseases, 33(suppl 2), 13-24. https://doi.org/10.1159/000440706

Karlsen, T. H., Lammert, F., \& Thompson, R. J. (2015). Genetics of liver disease: From pathophysiology to clinical practice. In Journal of Hepatology (Vol. 62, Issue S1, pp. S6-S14). Elsevier. https://doi.org/10.1016/j.jhep.2015.02.025

Katsika, D., Magnusson, P., Krawczyk, M., Grünhage, F., Lichtenstein, P., Einarsson, C., Lammert, F., \& Marschall, H. U. (2010). Gallstone disease in Swedish twins: Risk is associated with ABCG8 D19H genotype. Journal of Internal Medicine, 268(3), 279-285. https://doi.org/10.1111/j.1365-2796.2010.02249.x

Kienhuis, A. S., Vitins, A. P., Pennings, J. L. A., Pronk, T. E., Speksnijder, E. N., Roodbergen, M., van Delft, J. H. M., Luijten, M., \& van der Ven, L. T. M. (2013). Cyclosporine A treated in vitro 
models induce cholestasis response through comparison of phenotype-directed gene expression analysis of in vivo Cyclosporine A-induced cholestasis. Toxicology Letters, 221(3), 225-236. https://doi.org/10.1016/j.toxlet.2013.06.236

Kim, Y. C., Jung, H., Seok, S., Zhang, Y., Ma, J., Li, T., Kemper, B., \& Kemper, J. K. (2020). MicroRNA-210 Promotes Bile Acid-Induced Cholestatic Liver Injury by Targeting MixedLineage Leukemia-4 Methyltransferase in Mice. Hepatology, 71(6), 2118-2134. https://doi.org/10.1002/hep.30966

Krawczyk, M., Müllenbach, R., Weber, S. N., Zimmer, V., \& Lammert, F. (2010). Genome-wide association studies and genetic risk assessment of liver diseases. Nature Reviews Gastroenterology and Hepatology, 7(12), 669-681. https://doi.org/10.1038/nrgastro.2010.170

Krishna, R. G., \& Wold, F. (2006). Post-Translational Modification of Proteins. In Advances in Enzymology and Related Areas of Molecular Biology (Vol. 67, pp. 265-298). Wiley Blackwell. https://doi.org/10.1002/9780470123133.ch3

Lankisch, T. O., Metzger, J., Negm, A. A., Vokuhl, K., Schiffer, E., Siwy, J., Weismüller, T. J., Schneider, A. S., Thedieck, K., Baumeister, R., Zürbig, P., Weissinger, E. M., Manns, M. P., Mischak, H., \& Wedemeyer, J. (2011). Bile proteomic profiles differentiate cholangiocarcinoma from primary sclerosing cholangitis and choledocholithiasis. Hepatology, 53(3), 875-884. https://doi.org/10.1002/hep.24103

Lefkowitch, J. H. (2004). Histological assessment of cholestasis. Clinics in Liver Disease, 8(1), 27-40. https://doi.org/10.1016/S1089-3261(03)00138-7

Levy, C., \& Lindor, K. D. (2003). Management of osteoporosis, fat-soluble vitamin deficiencies, and hyperlipidemia in primary biliary cirrhosis. In Clinics in Liver Disease (Vol. 7, Issue 4, pp. 901910). https://doi.org/10.1016/S1089-3261(03)00097-7

Li, J., Jin, H., \& Wang, X. (2014). Epigenetic Biomarkers: Potential Applications in Gastrointestinal Cancers. ISRN Gastroenterology, 2014, 1-10. https://doi.org/10.1155/2014/464015

Li, Q., Ge, X., Xu, X., Zhong, Y., \& Qie, Z. (2014). Comparison of the gene expression profiles between gallstones and gallbladder polyps. International Journal of Clinical and Experimental Pathology, 7(11), 8016-8023. www.ijcep.com/ 
Li, X., \& Liu, R. (2020). Long non-coding RNA H19 in the liver-gut axis: A diagnostic marker and therapeutic target for liver diseases. In Experimental and Molecular Pathology (Vol. 115, p. 104472). Academic Press. https://doi.org/10.1016/j.yexmp.2020.104472

Lian, J. S., Liu, W., Hao, S. R., Chen, D. Y., Wang, Y. Y., Yang, J. Le, Jia, H. Y., \& Huang, J. R. (2015). A serum metabolomic analysis for diagnosis and biomarker discovery of primary biliary cirrhosis and autoimmune hepatitis. Hepatobiliary and Pancreatic Diseases International, 14(4), 413-421. https://doi.org/10.1016/S1499-3872(15)60393-9

Lindblom, P., Rafter, I., Copley, C., Andersson, U., Hedberg, J. J., Berg, A. L., Samuelsson, A., Hellmold, H., Cotgreave, I., \& Glinghammar, B. (2007). Isoforms of alanine aminotransferases in human tissues and serum-Differential tissue expression using novel antibodies. Archives of Biochemistry and Biophysics, 466(1), 66-77. https://doi.org/10.1016/j.abb.2007.07.023

Liu, J. Z., Hov, J. R., Folseraas, T., Ellinghaus, E., Rushbrook, S. M., Doncheva, N. T., Andreassen, O. A., Weersma, R. K., Weismüller, T. J., Eksteen, B., Invernizzi, P., Hirschfield, G. M., Gotthardt, D. N., Pares, A., Ellinghaus, D., Shah, T., Juran, B. D., Milkiewicz, P., Rust, C., ... Karlsen, T. H. (2013). Dense genotyping of immune-related disease regions identifies nine new risk loci for primary sclerosing cholangitis. Nature Genetics, 45(6), 670-675. https://doi.org/10.1038/ng.2616

Long, Y., Dong, X., Yuan, Y., Huang, J., Song, J., Sun, Y., Lu, Z., Yang, L., \& Yu, W. (2015). Metabolomics changes in a rat model of obstructive jaundice: Mapping to metabolism of amino acids, carbohydrates and lipids as well as oxidative stress. Journal of Clinical Biochemistry and Nutrition, 57(1), 50-59. https://doi.org/10.3164/jcbn.14-147

Lu, L. G., Chen, C. W., Cheng, J., Dou, X. G., Duan, Z. P., Fan, J. G., Fu, Q. C., Gao, C. F., Han, T., Han, Y., Hou, J. L., Hu, H. P., Hu, X. Q., Huang, J. R., Jia, J. D., Liu, Y. L., Ma, X., Mao, Y. M., Nan, Y. M., ... Zou, X. P. (2016). Consensus on the diagnosis and treatment of cholestatic liver diseases (2015, China). Journal of Digestive Diseases, 17(3), 137-154. https://doi.org/10.1111/1751-2980.12333

Marrer, E., \& Dieterle, F. (2010). Impact of biomarker development on drug safety assessment. In Toxicology and applied pharmacology (Vol. 243, Issue 2, pp. 167-179). 
https://doi.org/10.1016/j.taap.2009.12.015

Mas, V. R., Fisher, R. A., Archer, K. J., \& Maluf, D. G. (2009). Proteomics and liver fibrosis: Identifying markers of fibrogenesis. Expert Review of Proteomics, 6(4), 421-431. https://doi.org/10.1586/epr.09.59

Matthews, H., Hanison, J., \& Nirmalan, N. (2016). “Omics”-informed drug and biomarker discovery: Opportunities, challenges and future perspectives. In Proteomes (Vol. 4, Issue 28). MDPI AG. https://doi.org/10.3390/proteomes4030028

Metzger, J., Negm, A. A., Plentz, R. R., Weismüller, T. J., Wedemeyer, J., Karlsen, T. H., Dakna, M., Mullen, W., Mischak, H., Manns, M. P., \& Lankisch, T. O. (2013). Urine proteomic analysis differentiates cholangiocarcinoma from primary sclerosing cholangitis and other benign biliary disorders. Gut, 62(1), 122-130. https://doi.org/10.1136/gutjnl-2012-302047

Mortazavi, A., Williams, B. A., McCue, K., Schaeffer, L., \& Wold, B. (2008). Mapping and quantifying mammalian transcriptomes by RNA-Seq. Nature Methods, 5(7), 621-628. https://doi.org/10.1038/nmeth.1226

Müllenbach, R., \& Lammert, F. (2011). An update on genetic analysis of cholestatic liver diseases: Digging deeper. Digestive Diseases, 29(1), 72-77. https://doi.org/10.1159/000324137

Nallagangula, K. S., Shashidhar, K. N., Lakshmaiah, V., \& Muninarayana. (2018). Evolution of proteomic biomarker for chronic liver disease: Promise into reality. In Journal of Circulating Biomarkers (Vol. 7). SAGE Publications Ltd. https://doi.org/10.1177/1849454418777186

Navaneethan, U., Lourdusamy, V., Venkatesh, P. G. K., Willard, B., Sanaka, M. R., \& Parsi, M. A. (2015). Bile proteomics for differentiation of malignant from benign biliary strictures: A pilot study. Gastroenterology Report, 3(2), 136-143. https://doi.org/10.1093/gastro/gou066

Nguyen, K. D., Sundaram, V., \& Ayoub, W. S. (2014). Atypical causes of cholestasis. World Journal of Gastroenterology, 20(28), 9418-9426. https://doi.org/10.3748/wjg.v20.i28.9418

Nicholson, J. K., Lindon, J. C., \& Holmes, E. (1999). "Metabonomics": Understanding the metabolic responses of living systems to pathophysiological stimuli via multivariate statistical analysis of biological NMR spectroscopic data. Xenobiotica, 29(11), 1181-1189.

https://doi.org/10.1080/004982599238047 
Nicholson, Jeremy K., \& Lindon, J. C. (2008). Systems biology: Metabonomics. Nature, 455, 1054 1056. https://doi.org/10.1007/978-3-319-89321-1_6

Niu, L., Geyer, P. E. ., \& Mann, M. (2018). Proteomics in the Study of Liver Diseases. In The Human Gut-Liver-Axis in Health and Disease. https://doi.org/10.1007/978-3-319-98890-0

Noor, F. (2015). A shift in paradigm towards human biology-based systems for cholestatic-liver diseases. Journal of Physiology, 593(23), 5043-5055. https://doi.org/10.1113/JP271124

Novogrodsky, A., Tate, S. S., \& Meister, A. (1976). $\gamma$ Glutamyl transpeptidase, a lymphoid cell surface marker: relationship to blastogenesis, differentiation, and neoplasia. Proceedings of the National Academy of Sciences of the United States of America, 73(7), 2414-2418. https://doi.org/10.1073/pnas.73.7.2414

Oliver, S. G. (2002). Functional genomics: Lessons from yeast. Philosophical Transactions of the Royal Society B: Biological Sciences, 357(1417), 17-23. https://doi.org/10.1098/rstb.2001.1049

Onofrio, F. Q., \& Hirschfield, G. M. (2020). The Pathophysiology of Cholestasis and Its Relevance to Clinical Practice. In Clinical Liver Disease (Vol. 15, Issue 3, pp. 110-114). https://doi.org/10.1002/cld.894

Ostrowski, J., Goryca, K., Lazowska, I., Rogowska, A., Paziewska, A., Dabrowska, M., Ambrozkiewicz, F., Karczmarski, J., Balabas, A., Kluska, A., Piatkowska, M., Zeber-Lubecka, N., Kulecka, M., Habior, A., Mikula, M., Walewska-Zielecka, B., Krawczyk, M., Cichoz-Lach, H., Milkiewicz, P., ... Starzynska, T. (2019). Common functional alterations identified in blood transcriptome of autoimmune cholestatic liver and inflammatory bowel diseases. Scientific Reports, 9(1), 7190. https://doi.org/10.1038/s41598-019-43699-1

Ozer, J., Ratner, M., Shaw, M., Bailey, W., \& Schomaker, S. (2008). The current state of serum biomarkers of hepatotoxicity. Toxicology, 245(3), 194-205. https://doi.org/10.1016/j.tox.2007.11.021

Parent, R., \& Beretta, L. (2005). Proteomics in the study of liver pathology. Journal of Hepatology, 43(1), 177-183. https://doi.org/10.1016/j.jhep.2005.04.001

Patel, K., \& Sebastiani, G. (2020). Limitations of Noninvasive Tests for Assessment of Liver Fibrosis. JHEP Reports, 2(2), 100067. https://doi.org/10.1016/j.jhepr.2020.100067 
Pertea, M. (2012). The human transcriptome: An unfinished story. In Genes (Vol. 3, Issue 3, pp. 344 360). Multidisciplinary Digital Publishing Institute (MDPI). https://doi.org/10.3390/genes3030344

Phillips, J. R., Angulo, P., Petterson, T., \& Lindor, K. D. (2001). Fat-soluble vitamin levels in patients with primary biliary cirrhosis. The American Journal of Gastroenterology, 96(9), 2745-2750. https://doi.org/10.1111/j.1572-0241.2001.04134.x

Pirola, C. J., \& Sookoian, S. (2018). Multiomics biomarkers for the prediction of nonalcoholic fatty liver disease severity. World J Gastroenterol, 24(15), 1601-1615. https://doi.org/10.3748/wjg.v24.i15.1601

Pollock, G., \& Minuk, G. Y. (2017). Diagnostic considerations for cholestatic liver disease. In Journal of Gastroenterology and Hepatology (Australia) (Vol. 32, Issue 7, pp. 1303-1309). Blackwell Publishing. https://doi.org/10.1111/jgh.13738

Price, C. P. (1993). Multiple forms of human serum alkaline phosphatase: Detection and quantitation. In Annals of Clinical Biochemistry (Vol. 30, Issue 4, pp. 355-372). https://doi.org/10.1177/000456329303000403

Ramaiah, S. K. (2007). A toxicologist guide to the diagnostic interpretation of hepatic biochemical parameters. In Food and Chemical Toxicology (Vol. 45, Issue 9, pp. 1551-1557). https://doi.org/10.1016/j.fct.2007.06.007

Reichert, M. C., Hall, R. A., Krawczyk, M., \& Lammert, F. (2018). Genetic determinants of cholangiopathies: Molecular and systems genetics. In Biochimica et Biophysica Acta - Molecular Basis of Disease (Vol. 1864, Issue 4, pp. 1484-1490). Elsevier B.V. https://doi.org/10.1016/j.bbadis.2017.07.029

Reichling, J. J., \& Kaplan, M. M. (1988). Clinical use of serum enzymes in liver disease. In Digestive Diseases and Sciences (Vol. 33, Issue 12, pp. 1601-1614). Kluwer Academic Publishers-Plenum Publishers. https://doi.org/10.1007/BF01535953

Rockey, D. C., Caldwell, S. H., Goodman, Z. D., Nelson, R. C., \& Smith, A. D. (2009). Liver biopsy. Hepatology, 49(3), 1017-1044. https://doi.org/10.1002/hep.22742

Rodrigues, R. M., Kollipara, L., Chaudhari, U., Sachinidis, A., Zahedi, R. P., Sickmann, A., Kopp- 
Schneider, A., Jiang, X., Keun, H., Hengstler, J., Oorts, M., Annaert, P., Hoeben, E., Gijbels, E., De Kock, J., Vanhaecke, T., Rogiers, V., \& Vinken, M. (2018). Omics-based responses induced by bosentan in human hepatoma HepaRG cell cultures. Archives of Toxicology, 92(6), 19391952. https://doi.org/10.1007/s00204-018-2214-z

Rogoveanu, I., Gheonea, D. I., Săftoiu, A., \& Ciurea, T. (2006). The role of imaging methods in identifying the causes of extrahepatic cholestasis. In Journal of Gastrointestinal and Liver Diseases (Vol. 15, Issue 3, pp. 265-271).

Schena, M., Shalon, D., Davis, R. W., \& Brown, P. O. (1995). Quantitative monitoring of gene expression patterns with a complementary DNA microarray. Science, 270(5235), 467-470. https://doi.org/10.1126/science.270.5235.467

Schork, N. (2015). Personalized medicine: Time for one-person trials. In Nature (pp. 609-611). https://doi.org/10.1038/520609a

Shah, R., \& John, S. (2018). Cholestatic Jaundice (Cholestasis, Cholestatic Hepatitis). In StatPearls. StatPearls Publishing. http://www.ncbi.nlm.nih.gov/pubmed/29489239

Sharma, U., Pal, D., \& Prasad, R. (2014). Alkaline phosphatase: An overview. In Indian Journal of Clinical Biochemistry (Vol. 29, Issue 3, pp. 269-278). Springer India. https://doi.org/10.1007/s12291-013-0408-y

Sheehan, M., \& Haythorn, P. (1979). Predictive values of various liver function tests with respect to the diagnosis of liver disease. Clinical Biochemistry, 12(6), 262-263. https://doi.org/10.1016/S0009-9120(79)80122-8

Sinclair, K., \& Dudley, E. (2019). Metabolomics and Biomarker Discovery. Advances in Experimental Medicine and Biology, 1140, 289-298. https://doi.org/10.1007/978-3-030-15950-4

Singh, K. (2013). Evaluation and interpretation of biomarkers of liver diseases. International Journal of Research in Health Sciences, 1(3), 213-223.

Smith, G. S., Walter, G. L., \& Walker, R. M. (2013). Clinical Pathology in Non-Clinical Toxicology Testing. In Haschek and Rousseaux's Handbook of Toxicologic Pathology (Third Edit). Elsevier. https://doi.org/10.1016/B978-0-12-415759-0.00018-2

Smith, Z., Ryerson, D., \& Kemper, J. K. (2013). Epigenomic regulation of bile acid metabolism: 
Emerging role of transcriptional cofactors. In Molecular and Cellular Endocrinology (Vol. 368, Issues 1-2, pp. 59-70). NIH Public Access. https://doi.org/10.1016/j.mce.2012.04.008 Sotil, E. U., \& Jensen, D. M. (2004). Serum enzymes associated with cholestasis. Clinics in Liver Disease, 8(1), 41-54. https://doi.org/10.1016/S1089-3261(03)00136-3

Stokes, C. S., Krawczyk, M., \& Lammert, F. (2011). Gallstones: Environment, lifestyle and genes. Digestive Diseases, 29(2), 191-201. https://doi.org/10.1159/000323885

Strimbu, K., \& Tavel, J. A. (2010a). What are biomarkers? In Current Opinion in HIV and AIDS (Vol. 5, Issue 6, pp. 463-466). https://doi.org/10.1097/COH.0b013e32833ed177

Strimbu, K., \& Tavel, J. A. (2010b). What are biomarkers? In Current Opinion in HIV and AIDS (Vol. 5, Issue 6, pp. 463-466). NIH Public Access. https://doi.org/10.1097/COH.0b013e32833ed177

Sun, J., Wang, J., Zhang, N., Yang, R., Chen, K., \& Kong, D. (2019). Identification of global mRNA expression profiles and comprehensive bioinformatic analyses of abnormally expressed genes in cholestatic liver disease. Gene, 707, 9-21. https://doi.org/10.1016/j.gene.2019.04.078

Szalowska, E., Stoopen, G., Groot, M. J., Hendriksen, P. J., \& Peijnenburg, A. A. (2013). Treatment of mouse liver slices with cholestatic hepatotoxicants results in down-regulation of Fxr and its target genes. BMC Medical Genomics, 6(1), 1. https://doi.org/10.1186/1755-8794-6-39

Tabibian, J. H., Trussoni, C. E., O’Hara, S. P., Splinter, P. L., Heimbach, J. K., \& LaRusso, N. F. (2014). Characterization of cultured cholangiocytes isolated from livers of patients with primary sclerosing cholangitis. Laboratory Investigation, 94(10), 1126-1133. https://doi.org/10.1038/labinvest.2014.94

Tan, D., \& Goodman, Z. D. (2018). Liver Biopsy in Primary Biliary Cholangitis: Indications and Interpretation. Clinics in Liver Disease, 22(3), 579-588. https://doi.org/10.1016/j.cld.2018.03.008

Tang, Y. M., Wang, J. P., Bao, W. M., Yang, J. H., Ma, L. K., Yang, J., Chen, H., Xu, Y., Yang, L. H., Li, W., Zhu, Y. P., \& Cheng, J. Bin. (2015). Urine and serum metabolomic profiling reveals that bile acids and carnitine may be potential biomarkers of primary biliary cirrhosis. International Journal of Molecular Medicine, 36(2), 377-385. https://doi.org/10.3892/ijmm.2015.2233

Tapper, E. B., \& Lok, A. S. F. (2017). Use of liver imaging and biopsy in clinical practice. In D. L. 
Longo (Ed.), New England Journal of Medicine (Vol. 377, Issue 8, pp. 756-768). Massachussetts Medical Society. https://doi.org/10.1056/NEJMra1610570

Teng, P. N., Bateman, N. W., Hood, B. L., \& Conrads, T. P. (2010). Advances in proximal fluid proteomics for disease biomarker discovery. Journal of Proteome Research, 9(12), 6091-6100. https://doi.org/10.1021/pr100904q

The French METAVIR Cooperative Study Group. (1994). Intraobserver and interobserver variations in liver biopsy interpretation in patients with chronic hepatitis C. Hepatology (Baltimore, Md.), 20(1 Pt 1), 15-20. http://www.ncbi.nlm.nih.gov/pubmed/8020885

Toosi, A. E. K. (2015). Liver Fibrosis: Causes and Methods of Assessment, A Review. Romanian Journal of Internal Medicine, 53(4), 304-314. https://doi.org/10.1515/rjim-2015-0039

Trivedi, P. J., \& Hirschfield, G. M. (2016). The Immunogenetics of Autoimmune Cholestasis. In Clinics in Liver Disease (Vol. 20, Issue 1, pp. 15-31). W.B. Saunders. https://doi.org/10.1016/j.cld.2015.08.002

Trottier, J., Białek, A., Caron, P., Straka, R. J., Heathcote, J., Milkiewicz, P., \& Barbier, O. (2012). Metabolomic profiling of 17 bile acids in serum from patients with primary biliary cirrhosis and primary sclerosing cholangitis: A pilot study. Digestive and Liver Disease, 44(4), 303-310. https://doi.org/10.1016/j.dld.2011.10.025

Tyers, M., \& Mann, M. (2003). From genomics to proteomics. 422(March), 193-197. https://doi.org/10.1038/nature01510

Van den Hof, W. F. P. M., Coonen, M. L. J., van Herwijnen, M., Brauers, K., Jennen, D., Olde Damink, S. W. M., Schaap, F. G., \& Kleinjans, J. C. S. (2017). Validation of gene expression profiles from cholestatic hepatotoxicants in vitro against human in vivo cholestasis. Toxicology in Vitro, 44, 322-329. https://doi.org/10.1016/j.tiv.2017.07.024

Veenstra, T. D. (2007). Global and targeted quantitative proteomics for biomarker discovery. In Journal of Chromatography B: Analytical Technologies in the Biomedical and Life Sciences (Vol. 847, Issue 1, pp. 3-11). Elsevier. https://doi.org/10.1016/j.jchromb.2006.09.004 Vignoli, A., Orlandini, B., Tenori, L., Biagini, M. R., Milani, S., Renzi, D., Luchinat, C., \& Calabrò, A. S. (2019). Metabolic Signature of Primary Biliary Cholangitis and Its Comparison with Celiac 
Disease. Journal of Proteome Research, 18(3), 1228-1236.

https://doi.org/10.1021/acs.jproteome.8b00849

Villeneuve, D. L., Crump, D., Lia Garcia-Reyero, N., Hecker, M., Hutchinson, T. H., Lalone, C. A., Landesmann, B., Lettieri, T., Munn, S., Nepelska, M., Ottinger, M. A., Vergauwen, L., \& Whelan, M. (2014). Adverse Outcome Pathway (AOP) Development I: Strategies and Principles. TOXICOLOGICAL SCIENCES, 142(2), 312-320. https://doi.org/10.1093/toxsci/kfu199

Vinken, M., Maes, M., Vanhaecke, T., \& Rogiers, V. (2013). Drug-Induced Liver Injury: Mechanisms, Types and Biomarkers. Current Medicinal Chemistry, 20(24), 3011-3021. https://doi.org/10.2174/0929867311320240006

Vinken, Mathieu, Landesmann, B., Goumenou, M., Vinken, S., Shah, I., Jaeschke, H., Willett, C., Whelan, M., \& Rogiers, V. (2013). Development of an adverse outcome pathway from drugmediated bile salt export pump inhibition to cholestatic liver injury. Toxicological Sciences, 136(1), 97-106. https://doi.org/10.1093/toxsci/kft177

Vogel, C., \& Marcotte, E. M. (2012). Insights into the regulation of protein abundance from proteomic and transcriptomic analyses. Nature Reviews Genetics, 13(4), 227-232. https://doi.org/10.1038/nrg3185

Waddington, C. H. (2012). The epigenotype. 1942. International Journal of Epidemiology, 4l(1), 10 13. https://doi.org/10.1093/ije/dyr184

Wang, X. W., Heegaard, N. H. H., \& Orum, H. (2012). MicroRNAs in liver disease. In Gastroenterology (Vol. 142, Issue 7, pp. 1431-1443). W.B. Saunders. https://doi.org/10.1053/j.gastro.2012.04.007

Wang, Z., Gerstein, M., \& Snyder, M. (2009). RNA-Seq: A revolutionary tool for transcriptomics. In Nature Reviews Genetics (Vol. 10, Issue 1, pp. 57-63). NIH Public Access. https://doi.org/10.1038/nrg2484

Whitfield, J. B. (2001). Gamma glutamyl transferase. In Critical Reviews in Clinical Laboratory Sciences (Vol. 38, Issue 4, pp. 263-355). CRC Press LLC. https://doi.org/10.1080/20014091084227

Wishart, D. S., Feunang, Y. D., Marcu, A., Guo, A. C., Liang, K., ' Azquez-Fresno, R. V, Sajed, T., 
Johnson, D., Li, C., Karu, N., Sayeeda, Z., Lo, E., Assempour, N., Berjanskii, M., Singhal, S., Arndt, D., Liang, Y., Badran, H., Grant, J., ... Scalbert, A. (2018). HMDB 4.0: the human metabolome database for 2018. Nucleic Acids Research, 46. https://doi.org/10.1093/nar/gkx1089 Xiao, Y., Liu, R., Li, X., Gurley, E. C., Hylemon, P. B., Lu, Y., Zhou, H., \& Cai, W. (2019). Long Noncoding RNA H19 Contributes to Cholangiocyte Proliferation and Cholestatic Liver Fibrosis in Biliary Atresia. Hepatology, 70(5), 1658-1673. https://doi.org/10.1002/hep.30698

Yamazaki, M., Miyake, M., Sato, H., Masutomi, N., Tsutsui, N., Adam, K. P., Alexander, D. C., Lawton, K. A., Milburn, M. V., Ryals, J. A., Wulff, J. E., \& Guo, L. (2013). Perturbation of bile acid homeostasis is an early pathogenesis event of drug induced liver injury in rats. Toxicology and Applied Pharmacology, 268(1), 79-89. https://doi.org/10.1016/j.taap.2013.01.018

Yang, B., Liu, B., Bi, P., Wu, T., Wang, Q., \& Zhang, J. (2015). An integrated analysis of differential miRNA and mRNA expressions in human gallstones. Molecular BioSystems, 11(4), 1004-1011. https://doi.org/10.1039/c4mb00741g

Yang, R. Z., Blaileanu, G., Hansen, B. C., Shuldiner, A. R., \& Gong, D. W. (2002). cDNA cloning, genomic structure, chromosomal mapping, and functional expression of a novel human alanine aminotransferase. Genomics, 79(3), 445-450. https://doi.org/10.1006/geno.2002.6722

Yang, R., Zhao, Q., Hu, D. D., Xiao, X. R., Huang, J. F., \& Li, F. (2018). Metabolomic analysis of cholestatic liver damage in mice. Food and Chemical Toxicology, 120, 253-260. https://doi.org/10.1016/j.fct.2018.07.022

Yang, X., Kui, L., Tang, M., Li, D., Wei, K., Chen, W., Miao, J., \& Dong, Y. (2020). HighThroughput Transcriptome Profiling in Drug and Biomarker Discovery. In Frontiers in Genetics (Vol. 11, p. 19). Frontiers Media S.A. https://doi.org/10.3389/fgene.2020.00019

Yu, M., Zhu, Y., Cong, Q., \& Wu, C. (2017). Metabonomics Research Progress on Liver Diseases. Canadian Journal of Gastroenterology and Hepatology, 2017. https://doi.org/10.1155/2017/8467192

Zhang, Y., Liu, C., Barbier, O., Smalling, R., Tsuchiya, H., Lee, S., Delker, D., Zou, A., Hagedorn, C. H., \& Wang, L. (2016). Bcl2 is a critical regulator of bile acid homeostasis by dictating Shp and lncRNA H19 function. Scientific Reports, 6(1), 1-11. https://doi.org/10.1038/srep20559 
Zondervan, K. T., \& Cardon, L. R. (2004). The complex interplay among factors that influence allelic association. In Nature Reviews Genetics (Vol. 5, Issue 2, pp. 89-100). European Association for Cardio-Thoracic Surgery. https://doi.org/10.1038/nrg1270 
Table 1.

\begin{tabular}{|c|c|c|c|c|c|c|}
\hline Cholestatic disease & ALP & ALT & AST & GGT & Conjugated bilirubin & Other \\
\hline PBC & $\begin{array}{l}\geq 1.5 \times \text { ULN for at least } 6 \\
\text { months }\end{array}$ & Possibly increased & Possibly increased & Increased & $\begin{array}{l}\text { Possibly increased, especially } \\
\text { in advanced stages }\end{array}$ & $\begin{array}{l}\text { AMA titre } \geq 1: 40 \text { in } 90 \% \text { of individuals } \\
\text { ANA present in } 30 \% \text { of individuals } \\
\text { IgM increased } \\
\text { Cholesterol increased } \\
\text { Albumine levels altered in advanced stages }\end{array}$ \\
\hline PSC & Increased but can be normal & $\begin{array}{l}>2 \text { to } 3 \times \text { ULN, but can be } \\
\text { normal }\end{array}$ & $\begin{array}{l}>2 \text { to } 3 \times \text { ULN, but can be } \\
\text { normal }\end{array}$ & Increased & $\begin{array}{l}\text { Increased in 30\% of } \\
\text { individuals }\end{array}$ & $\begin{array}{l}\text { IgG increased in } 60 \% \text { of individuals } \\
\text { IgM increased in } 45 \% \text { of individuals } \\
\text { IgM increased in } 45 \% \text { of individuals } \\
\text { pANCA, ANA and SMA frequently present }\end{array}$ \\
\hline IgG4 associated cholangitis & Possibly increased & Possibly mildly increased & Possibly mildly increased & Possibly increased & Possibly increased & IgG4 increased in $90 \%$ of individuals \\
\hline PFIC type $1,2,3$ & Increased & Increased & Increased & $\begin{array}{l}\text { Type 1,2: decreased; type 3: } \\
\text { increased }\end{array}$ & $\begin{array}{l}\text { Increased in 30\% of } \\
\text { individuals }\end{array}$ & $\begin{array}{l}\text { BAs increased } \\
5^{\prime}-\mathrm{NT} \text { increased }\end{array}$ \\
\hline BRIC & $\geq 2$ to $40 \times$ ULN & Normal or mildly increased & Normal or mildly increased & Normal or minimally increased & Increased & BAs increased \\
\hline Alagille syndrome & $\begin{array}{l}\text { Increased (main contribution } \\
\text { by bone) }\end{array}$ & Increased & Increased & Increased & Normal & \begin{tabular}{|l|} 
Cholesterol increased \\
BAs increased
\end{tabular} \\
\hline DIC & \begin{tabular}{|l}
$>2 \times$ ULN or $($ ALT/ALP $)<$ \\
2 and both above ULN
\end{tabular} & $\begin{array}{l}\text { Normal or minimally } \\
\text { increased }\end{array}$ & $\begin{array}{l}\text { Normal or minimally } \\
\text { increased }\end{array}$ & $\begin{array}{l}\text { Increased depending on } \\
\text { subtype of DIC }\end{array}$ & Increased & $\begin{array}{l}\text { Cholesterol increased depending on subtype } \\
\text { of DIC }\end{array}$ \\
\hline ICP & $\begin{array}{l}\text { Increased (main contribution } \\
\text { by placenta) }\end{array}$ & Increased & Increased & Possibly increased & $\begin{array}{l}\text { Increased in } 10-15 \% \text { of } \\
\text { indviduals }\end{array}$ & BAs increased \\
\hline
\end{tabular}

Table 1. Serum levels of clinical chemistry biomarkers in cholestatic diseases.

Note: the table gives an overview of typical levels of serum clinical chemistry biomarkers observed in cholestatic diseases in the general population. Exceptionally normal serum levels can be observed.

5'-NT, 5'-nucleotidase; ALP, alkaline phosphatase; ALT, alanine aminotransferase; AMA, antimitochondrial antibodies; ANA, antinuclear antibodies; AST, aspartate aminotransferase; BA, bile acid; BRIC, benign recurrent intrahepatic cholestasis; CFALD, cystic fibrosis-associated liver disease; DIC, drug-induced cholestasis; GGT, $\gamma$-glutamyltransferase; ICP, intrahepatic cholestasis of pregnancy; Ig, immunoglobulin; pANCA, perinuclear antineutrophil cytoplasmic antibodies; PBC, primary biliary cholangitis; PFIC, progressive familial intrahepatic cholestasis; PSC, primary sclerosing cholangitis; SMA, smooth muscle antibodies; ULN, upper limit of normal 
Table 2.

\begin{tabular}{|c|c|}
\hline Cholestatic disease & Gene(s) affected \\
\hline Alagille syndrome & JAG1, NOTCH2 \\
\hline$\alpha 1$-antitrypsin deficiency & SERPINA1 \\
\hline Alpha-methylacyl-CoA racemase deficiency & $A M A C R$ \\
\hline Arthrogryposis-renal dysfunction-cholestasis syndrome & VIPAS39, VPS33B \\
\hline Autosomal recessive polycystic kidney disease & PKHD1 \\
\hline BA conjugation disorder & $S L C 27 A 5$ \\
\hline BA reabsorption disorder & SLC10A1, SLC10A2 \\
\hline BA receptor defect & GPBAR1 \\
\hline BA synthesis disorders & CYP7A1 \\
\hline Biliary atresia & $S L C 51 B$ \\
\hline BRIC & $A B C B 11, A T P 8 B 1, S L C 51 A$ \\
\hline Cerebrotendinous xanthomatosis & CYP27A1 \\
\hline Cholesteryl ester storage disease & $L I P A$ \\
\hline Citrullinemia & SLC25A13 \\
\hline Congenital bile acid synthesis defect & $\begin{array}{l}\text { ACOX2, AKR1D1, AMACR, CYP7B1, } \\
\text { HSD } 3 B 7\end{array}$ \\
\hline Cystic fibrosis & CFTR \\
\hline D-bifunctional protein deficiency & HSD $17 B 4$ \\
\hline Dubin-Johnson syndrome & $A B C C 2$ \\
\hline Extrahepatic cholestasis & $S L C 51 B$ \\
\hline Familial hypercholanemia & BAAT, TJP2 \\
\hline Lucey-Driscoll Syndrome & UGT1A1 \\
\hline Crigler-Najjar syndrome & UGT1A1 \\
\hline Fanconi renotubular syndrome 3 & EHHADH \\
\hline Gallbladder disease & $A B C B 4, A B C G 8$ \\
\hline Hereditary fructose intolerance & $A L D O B$ \\
\hline Ichthyosis, leukocyte vacuoles, alopecia, and sclerosing cholangitis & CLDN1 \\
\hline ICP & $A B C B 4, A T P 8 B 1$ \\
\hline Joubert syndrome & $C C 2 D 2 A, M K S 1, T M E M 216, N P H P 1$ \\
\hline Lipid storage disorder & $S C P 2$ \\
\hline Transient infantile liver failure & $T R M U$ \\
\hline Meckel syndrome & $C C 2 D 2 A, M K S 1, N P H P 3, T M E M 216$ \\
\hline Mitochondrial DNA depletion syndrome & DGUOK, POLG, MPV17 \\
\hline Neonatal sclerosing cholangitis & $D C D C 2$ \\
\hline Nephronophthisis & INVS, NPHP1, NPHP3, NPHP4 \\
\hline Niemann-Pick disease & NPC1, NPC2, SMPD1 \\
\hline North American Indian childhood cirrhosis & UTP4 \\
\hline Peroxisomal disorders & $\begin{array}{l}\text { PEX1, PEX10, PEX11B, PEX12, } \\
\text { PEX13, PEX14, PEX16, PEX19, PEX2, } \\
\text { PEX26, PEX3, PEX5, PEX6, PEX7 }\end{array}$ \\
\hline PFIC & $\begin{array}{l}A B C B 11, A B C B 4, S L C 51 A, T J P 2, \\
A T P 8 B 1, N R 1 H 4, M Y O 5 B\end{array}$ \\
\hline Renal cysts and diabetes syndrome & $H N F 1 B$ \\
\hline Renal-hepatic-pancreatic dysplasia 1 & NPHP3 \\
\hline
\end{tabular}




\begin{tabular}{|l|l|} 
Sitosterolemia & ABCG5, ABCG8 \\
\hline Smith-Lemli-Opitz syndrome & DHCR7 \\
\hline Transaldolase deficiency & TALDO1 \\
\hline Tyrosinemia type I & FAH \\
\hline
\end{tabular}

\section{Table 2. Genetic testing panel for cholestatic diseases.}

Overview of genes included in the genetic cholestasis testing panel and the corresponding cholestatic disease.

BA, bile acid; BRIC, benign recurrent intrahepatic cholestasis; ICP, intrahepatic cholestasis of pregnancy; PFIC, progressive familial intrahepatic cholestasis 
Table 3.

\begin{tabular}{|c|c|c|c|c|}
\hline Cellular response & Key event / Gene & AOP & $\begin{array}{c}\text { In vitro intrahepatic } \\
\text { cholestasis }\end{array}$ & $\begin{array}{c}\text { In vivo extrahepatic } \\
\text { cholestasis }\end{array}$ \\
\hline \multirow{8}{*}{ Deteriorative response } & Mitochondrial impairment & included & $\uparrow$ & $\uparrow$ \\
\hline & Inflammation & included & $\uparrow$ & $\uparrow$ \\
\hline & Oxidative stress & included & $\uparrow$ & $\uparrow$ \\
\hline & Endoplasmic reticulum stress/unfolded protein response & not included & $\uparrow$ & $\downarrow$ or $=$ \\
\hline & Apoptosis & not included & $\uparrow$ or $=$ & $=$ \\
\hline & Autophagy & not included & $\uparrow$ & $\uparrow$ \\
\hline & Necrosis & included & $\uparrow$ or $=$ & $=$ \\
\hline & Necroptosis & not included & $\uparrow$ & $\uparrow$ \\
\hline \multirow{11}{*}{ Adaptive response } & $A B C C 2 \mid A b c c 2$ & $\uparrow$ & $\uparrow$ or $\downarrow$ & $=$ \\
\hline & $A B C C 3 \mid A b c c 3$ & $\uparrow$ & $\downarrow$ & $\uparrow$ \\
\hline & CYP2B6|Cyp2b10 & $\uparrow$ & $\downarrow$ & $\downarrow$ \\
\hline & СYР3А4|Сyp3a11 & $\uparrow$ & $\downarrow$ & $=$ \\
\hline & СYР7А1|Сyp $7 a 1$ & $\downarrow$ & $\downarrow$ & $\uparrow$ \\
\hline & OATP1B1|Slcolb2 & $\downarrow$ & $\downarrow$ & $\downarrow$ \\
\hline & OST $\alpha \mid$ Ost $\alpha$ & $\uparrow$ & $\uparrow$ or $=$ & $=$ \\
\hline & $O S T \beta \mid O s t \beta$ & $\uparrow$ & $\uparrow$ or $=$ & $\uparrow$ \\
\hline & SLC10A1|Slc10a1 & $\downarrow$ & $\downarrow$ & $\downarrow$ \\
\hline & SULT2A1|Sult2a2 & $\uparrow$ & $\downarrow$ & $=$ \\
\hline & $U G T 2 B 4 \mid U g t 2 b 1$ & $\uparrow$ & $\downarrow$ & $\downarrow$ \\
\hline
\end{tabular}

Table 3. Robustness testing of the adverse outcome pathway (AOP) for cholestatic liver injury

An AOP for cholestatic liver injury was developed with BSEP inhibition as molecular initiating event. Key events in the resulting deteriorative response were identified, as well as altered gene expressions in the adaptive response.

The robustness of the AOP was tested in two models of cholestasis, in vitro intrahepatic and in vivo extrahepatic cholestasis, by transcriptomic analysis of genes involved in key events of the deteriorative response and altered genes in the adaptive response. 
Novel molecular mechanisms in the deteriorative response were identified and different gene expression profiles were found depending on the model used.

Human genes are presented with the respective mouse gene counterpart.

$\uparrow$, upregulated; $\downarrow$, downregulated; =, unaltered

ABCC2/3|Abcc2/3, ATP-binding cassette C2/3; BDL; bile duct ligation; CYP $\mid$ Cyp, cytochrome P450; DIC, drug-induced cholestasis; OATP1B1, organic anion transporting peptide 1B1; OST $\alpha / \beta \mid O s t \alpha / \beta$, organic solute transporter $\alpha / \beta$; Slcolb2, solute carrier organic anion transporter family member 1B2; SLC10A1|Slc10a1, solute carrier family 10 member 1; SULT2A1|Sult2a2, sulfotransferase 2 A1/2; UGT2B4|Ugt2b1, UDP glucuronosyltransferase 2 B1/4 